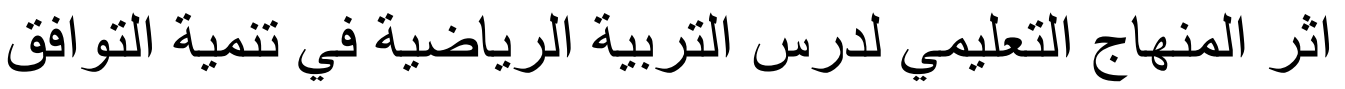

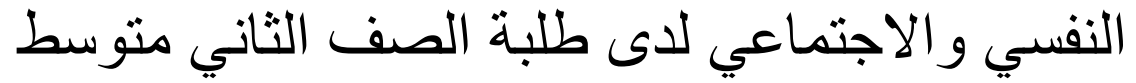

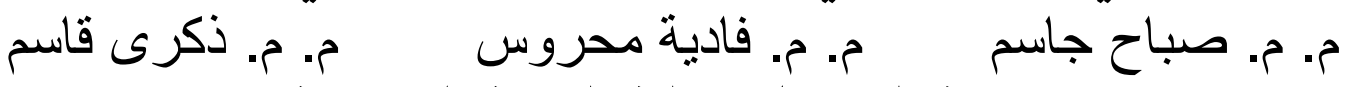
جامعة الموصل / كلية التربية الرياضية

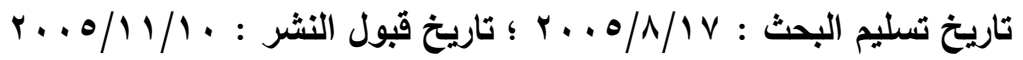

$$
\text { ملخص البحث: : هدف البحث إلى الكثف عن : }
$$

- مستوى التوافق النفسي والاجتماعي لدى طلبة الصف الثاني منوسط. - اثر المنهاج التعليمي لدرس التربية الرياضية في تتمية التوافق النفسي والاجتماعي لدى طلية لاعنية الصف الثاني منوسط.

استخدم الباحثتون المنهج التجريبي لملاءمته لطبيعة البحث. وانتشلت عينة البحث على

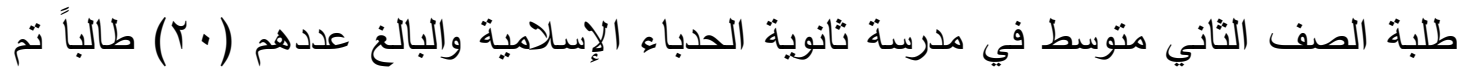
اختيارهم بالطريقة العمدية قسموا إلى مجموعتين (• (1) طلاب يمنلون المجموعة التجريبية و ( ( ) طلاب يمنلون المجموعة الضابطة. وتحقق الباحثون من تكافؤ المجموعتين التجريبية والضابطة،

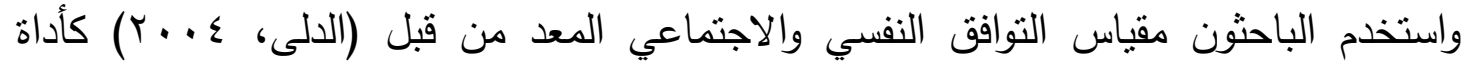
للبحث، وتم تطبيق البرنامج التعليمي لدرس التربية الرياضية على المجموعة التجريبية واستغرق

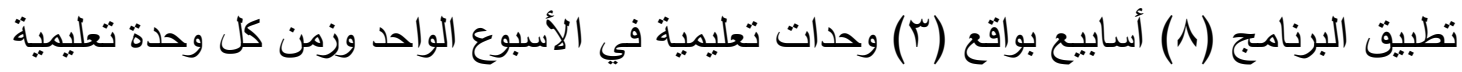

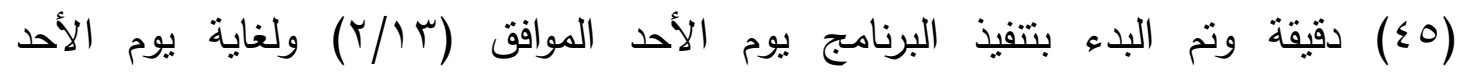

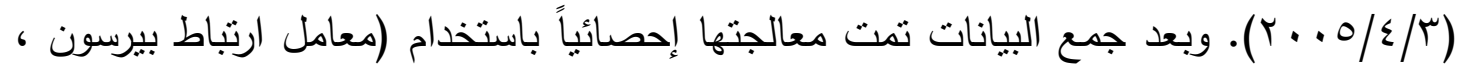
قانون النسبة المئوية، الوسط الحسابي، الانحراف المعياري، اختبار (ت) لوسطين حسابيين مرتبطين منساوبين العدد وغير منساويين العدد). واستتنج الباحثن: وجود فروق ذات دلالة معنوية بين المجموعتين التجريبية والضابطة بمستوى النوافق النفسي والاجتماعي ولصالح المجموعة التجريبية . وقد أوصى الباحثون بإعادة الدرس الرياضي الدنهي الأسبوعي في ثانوية الحدباء الإسلامية ، وإجراء دراسات مشابهة لدور الرياضة وعلاقتها بالمتغيرات الأخرى. 


\title{
The Effect of Learning Programme of Sport Lesson in Developing Social Psychological Harmony of Second Stage Students of Intermediate School
}

\author{
Assist. Lecturer \\ Assist. Lecturer \\ Sabah Jasim \\ Fadia Mahroos \\ University of Mosul - College of Sport Education \\ Assist. Lecturer \\ Thikra Qasim
}

\section{Abstract:}

The present research aimed at uncovering:

- The level of the social psychological harmony of the second stage students of Intermediate school.

- The effect of Learning Programme of Sport Lesson in Developing social psychological harmony of second stage students of Intermediate school.

Researchers used the experiment method due to its suitablity to the nature of the research the sample of the research included the second stage students of AL- Hadba Islamic Preparatory School Whose number was twenty. Those students were intertionally chosen and divided into two sets: (10) students represented the experimental set and (10) students represented control one. The researchers verified the equivalence of the two groups. They used the psychological and social scale prepared by (Adalli, 2004) as a tool to the research. The learing programme of sport lesson was applied to the experimental set. The programme took eight weeks: three learning units per week and each unit took (45) mins. the programme started on Sunday (13 / 2 / 2005) until Sunday (3 / 4 / 2005). After collecting all the data, they were processed statistically through the use of (person correlation factor, percentage rule, computing level, divergence criterion, $\mathrm{T}$ - test for two connected computing levels which are equal and inequal in number)

Rerearchers concluded: There are differences of clear signification between experimental and control sets in the same level of the psychological and social sets in favour of the testing experimental set.

Rerearchers recommend to: Return the weekly programmed sport lesson in Al- Hadba Islamic Preparatory school, Administer studies similar to the role of sport and its relationship to the other variables. 


\section{ا ـ التعريف بالبحث: ا ـ المقدمة و أهمية البحث:}

يعد التوافق النفسي والاجتماعي العملية الواعية المتكاملة الديناميكية المستمرة التي يسعى التئي

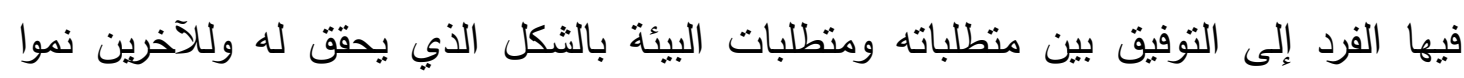

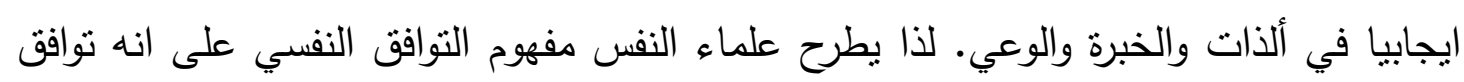

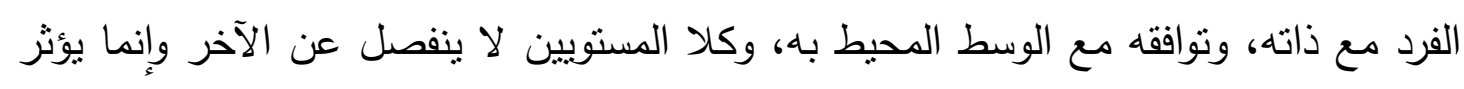

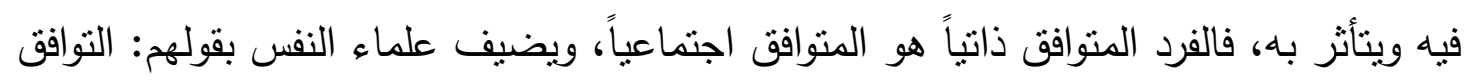

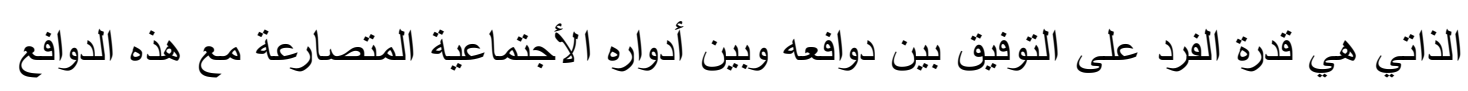

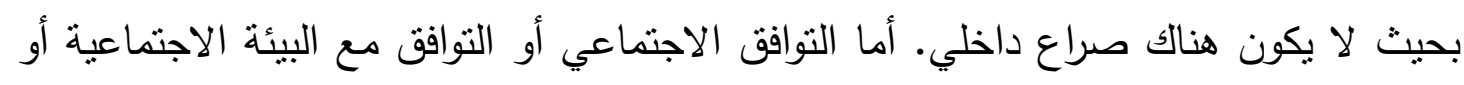

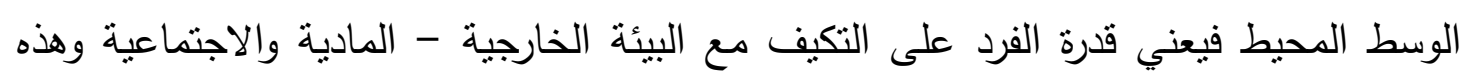

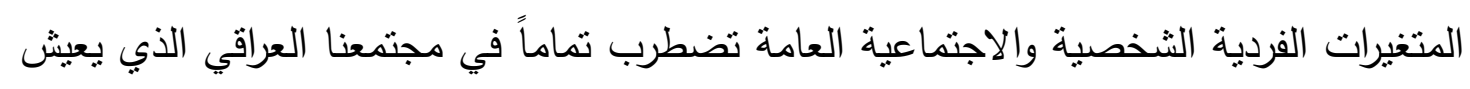
التحول في الفترة الراهنة والتي أسفرت عن تغيرات اجتماعية واقتصادية وثقافية وقيمية ملحوظة

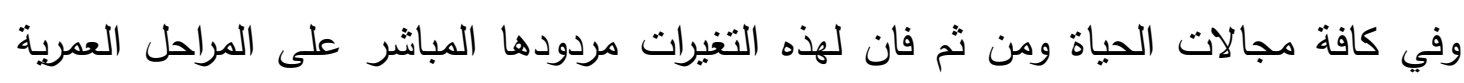

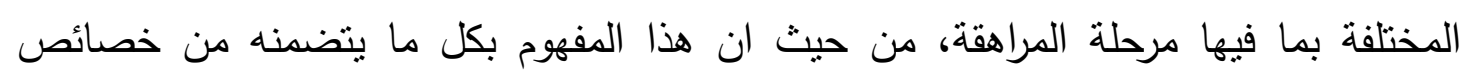

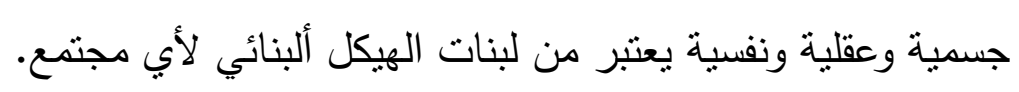

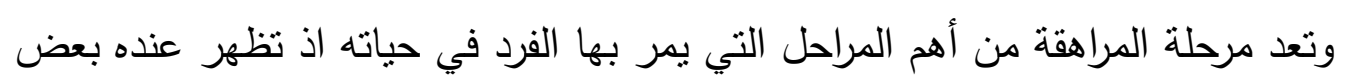

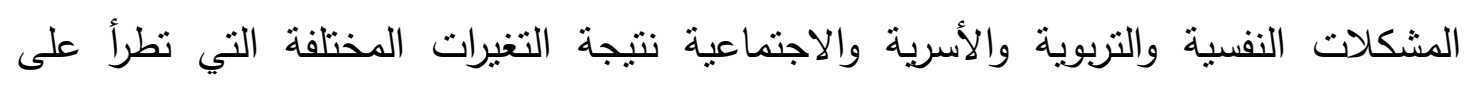
المراهق في هذه المرحلة، لذا فهو في اثد الحاجة إلى من بستمع إلى مشكلاته ويفهمه ويساعداه

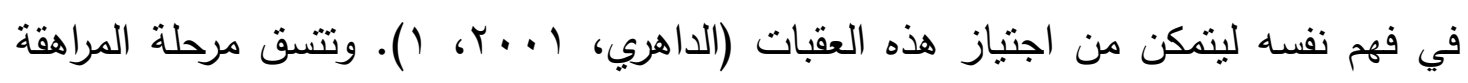

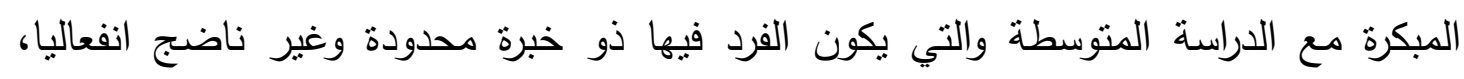

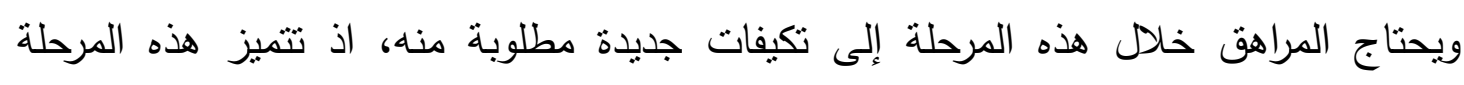

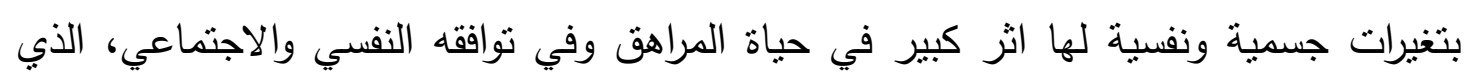

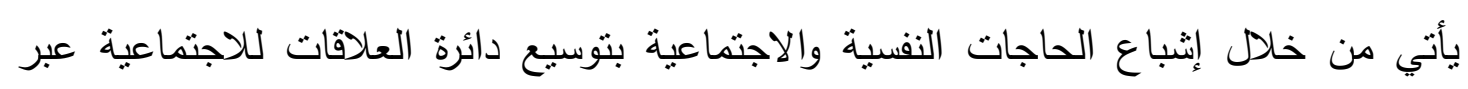

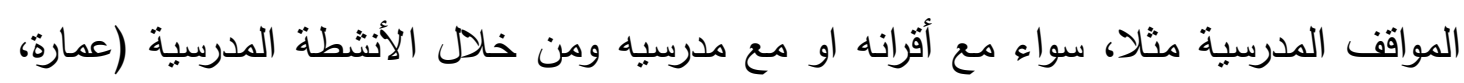

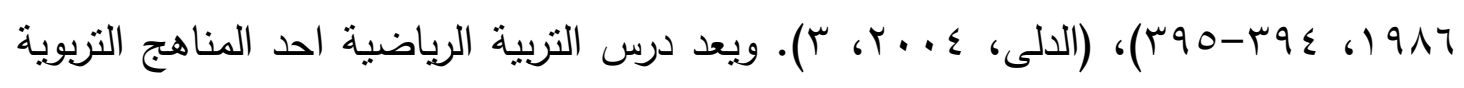

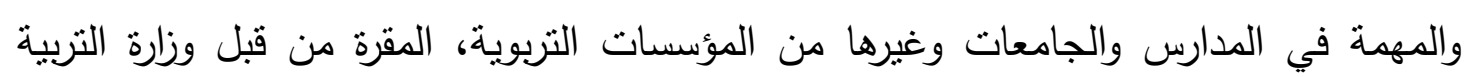

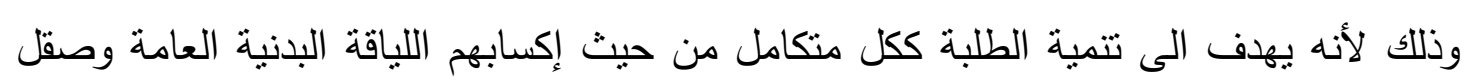
قدراتهم العقلية والفكرية وتهذيب سلوكهم العام، وضبط مظاهرهم الانفعالية والنفسية وتعديل

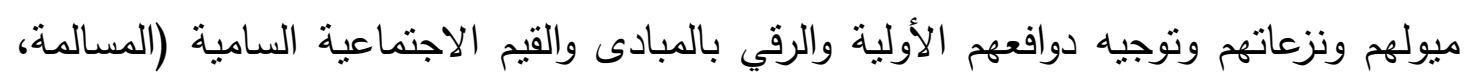

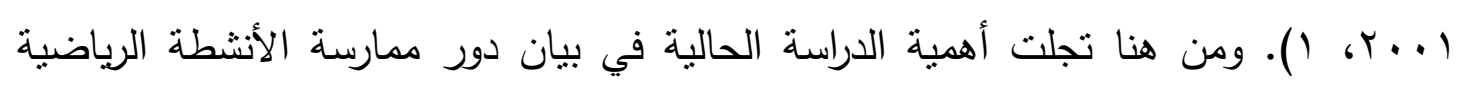


المدرسية المختلفة في تتمية التوافق النفسي والاجتماعي لدى طلاب الصف الثاني متوسط والذين

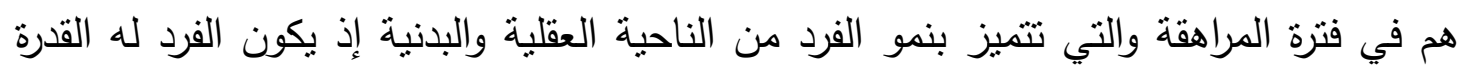

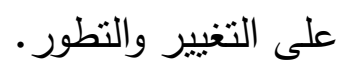

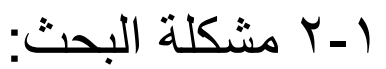
تبلورت مشكلة الدراسة الحالية في التعرف على دور البرنامج التعليمي لدرس التربية الرياضية الذي يعد احد الوسائل والطرائق المدرسية المناسبة للطلبة في مختلف المراحل العمرية في تتمية النوافق النفسي والاجتماعي لدى طلبة الصف الثاني متوسط، الذي يمتل بدوره العملية

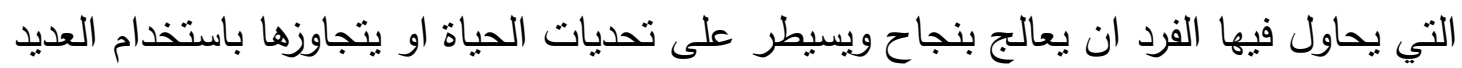
من الأساليب والاستراتيجيات المتتوعة التي تتطلب تغيرا مستمرا من جانب الفرد.

$$
\text { 1 ـ أهداف البحث: }
$$

1-r-1-1 مستوى النوافق النفسي والاجتماعي لدى طلبة الصف الثناني منتوسط.

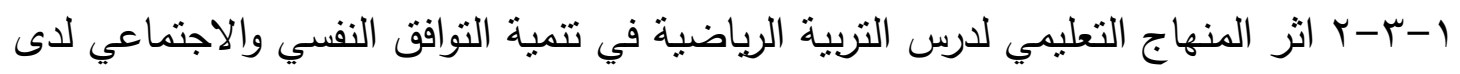
طلبة الصف الثاني متوسط.

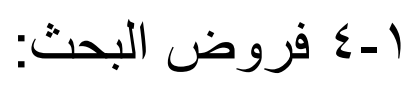

1-ع - ا وجود فروق ذات دلاللة إحصائية بين الاختبارين القبلي والبعدي للمجموعة التجريبية. 1-

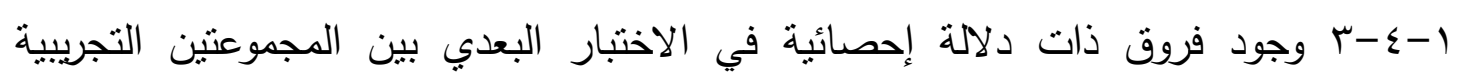
والضابطة.

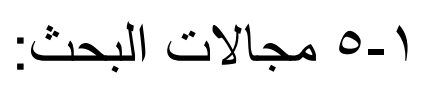

1-0-1 المجال البشري: طلاب الصف الثاني متوسط في مدرسة ثانوية الحدباء الإسلامية.

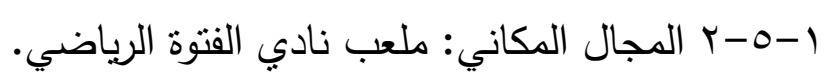

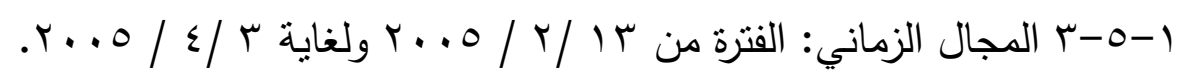
1 -7 تحديد المصطلحات: 
- التوافق النفسي والاجتماعي: هو تكيف الثخص ببيئته الاجتماعية في مجال حياته مع

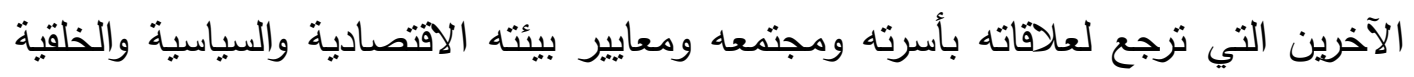

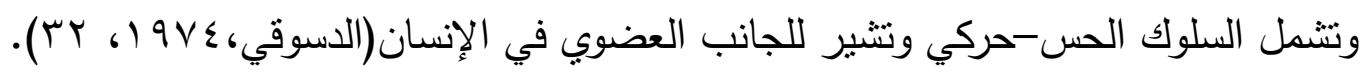

\section{Y - الإطار النظري و الدر اسات السابقة:}

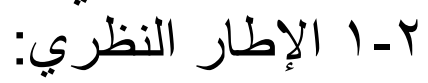
Y - ا - ا الإطار النظري للتو افق النفسي والاجتماعي:

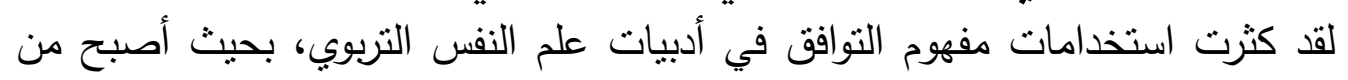

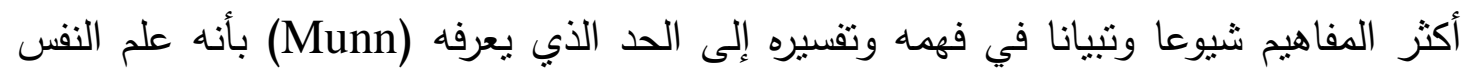

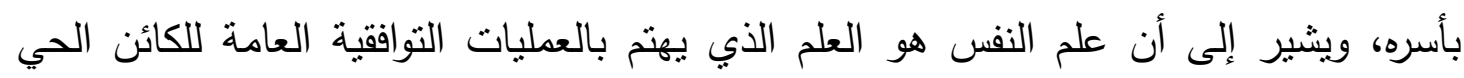

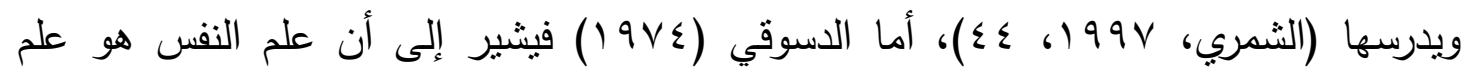

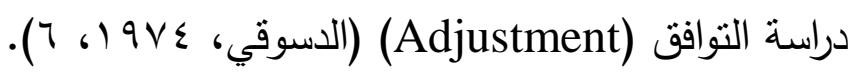

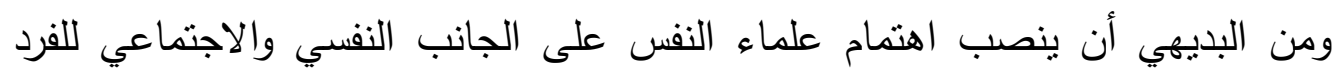

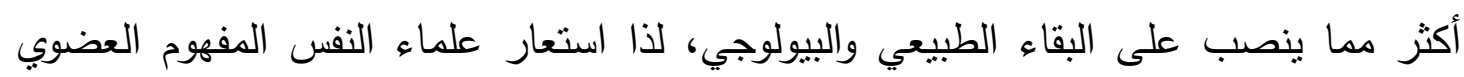

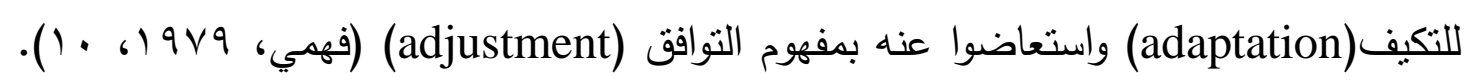
ويوجد هناك تذاخل بين مفهومي التكيف والتوافق حيث حدد كاتل (catell) معنى كل منهما

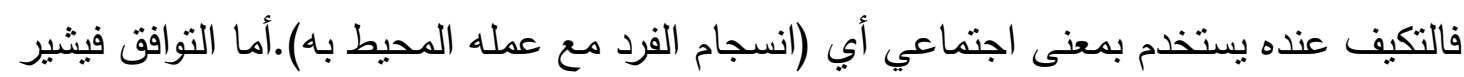

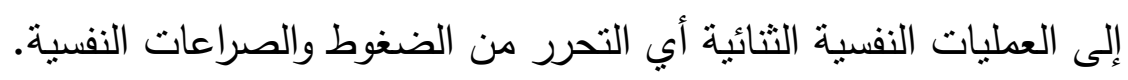

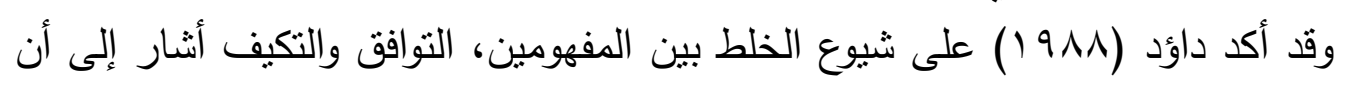

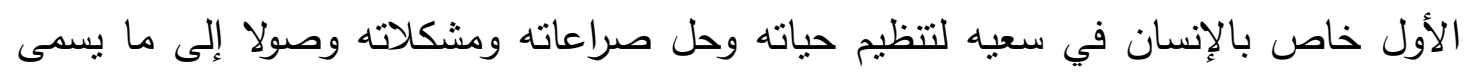

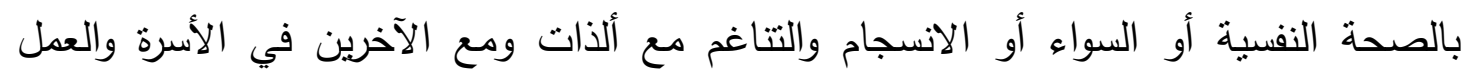

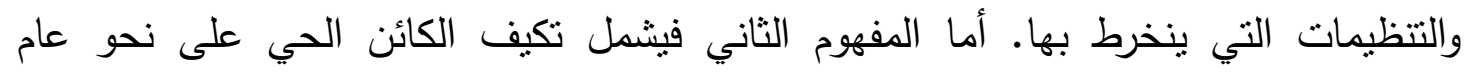

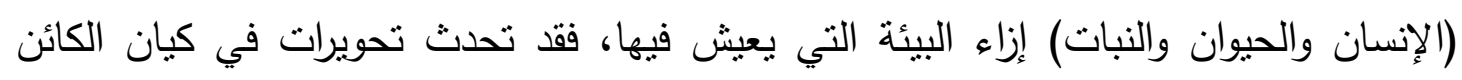

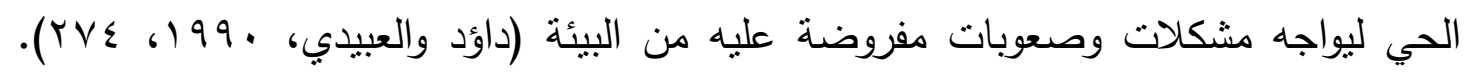

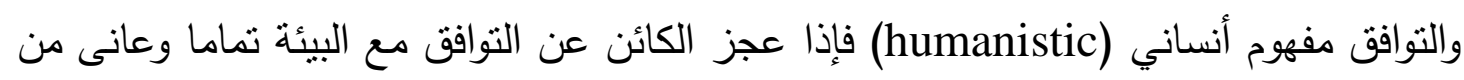

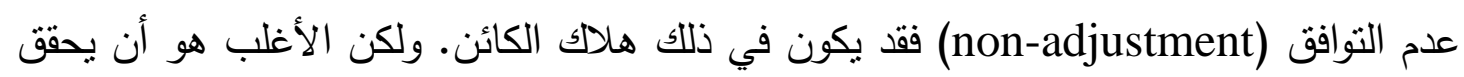

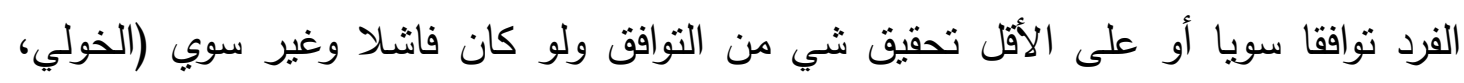

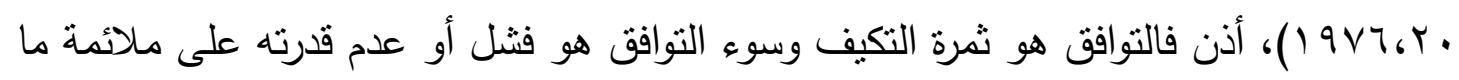

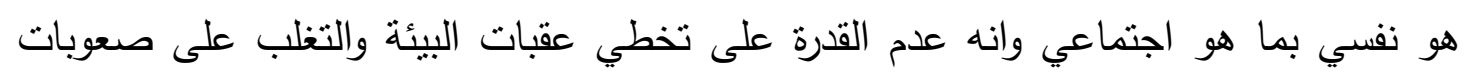

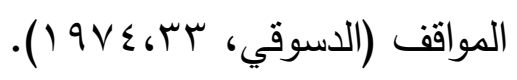




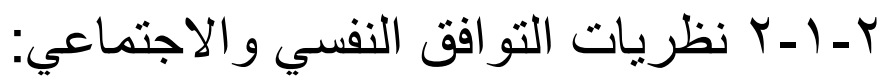

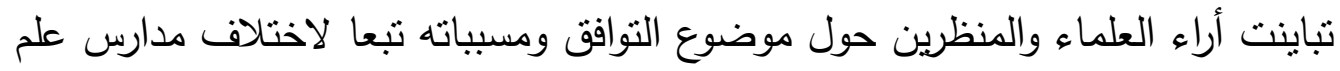

النفس الني ينتمي كل واحد منهم إليها، وفيما يأني استعراض لأهم تلك المدارس أو الناء النظريات:

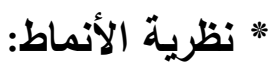

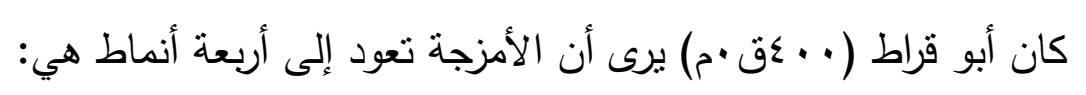

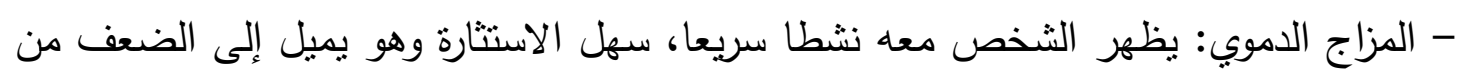

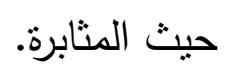

- المزاج الصفراوي: ويغلب عليه التسرع وقلة السرور، وشدة الانفعال (الرفاعي، 19AV، (1) 1 (1)

- المزاج السوداوي: نسبة إلى المرارة السوداء (الدم المتخثر في الطحال)،يتميز أصحابه بسرعة الاكتئاب وبط الاستثارة.

- المزاج البلغمي (الليمفاوي): يتميز أصحابه بالبلادة والبطء والضعف والانفعالات الهادئة.

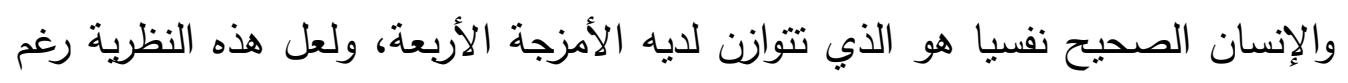

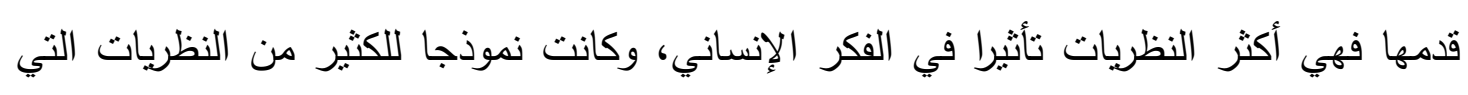

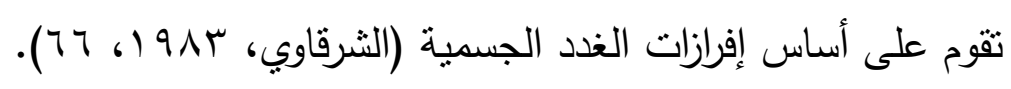

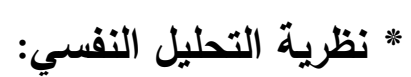

رائد هذه النظرية فرويد ومن أعلامها (الدلر، هورني، فروم، سيليفان) وينكون الجهاز

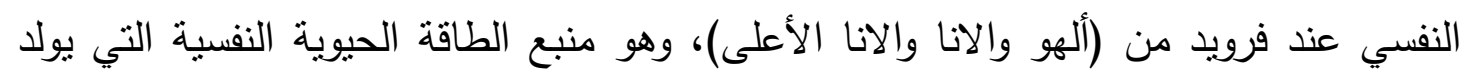

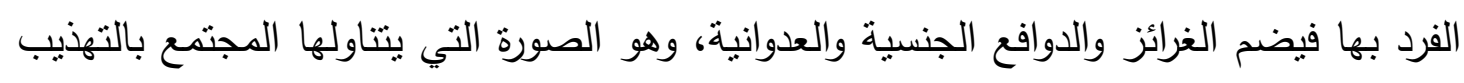

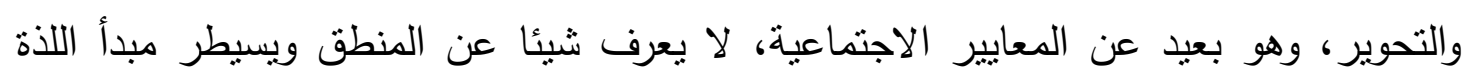

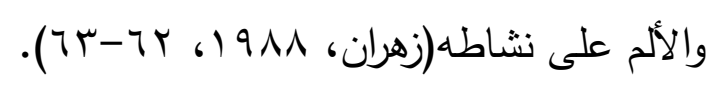

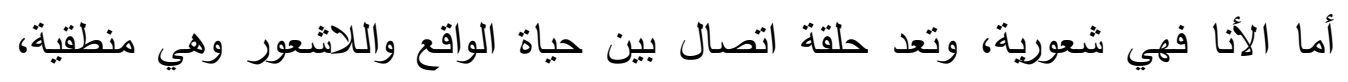

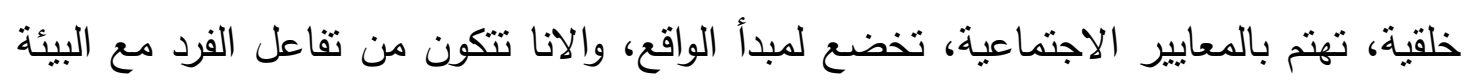

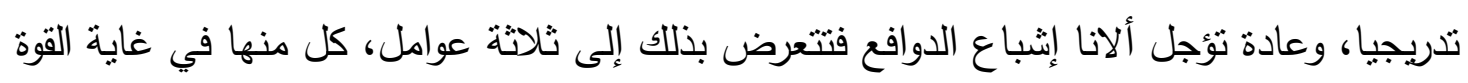

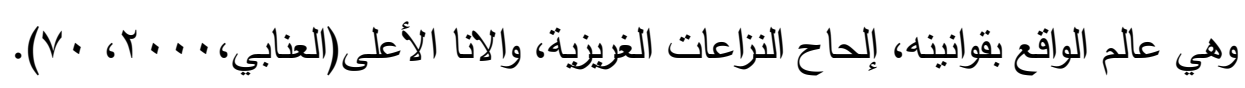

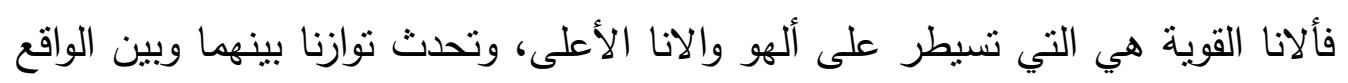

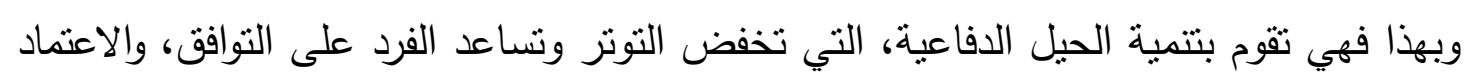

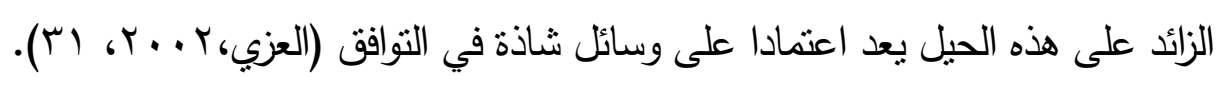

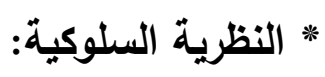


ترى هذه الددرسة أن السلوك متعلم من البيئة، وان عملية التعلم تحدث نتيجة وجود دافع

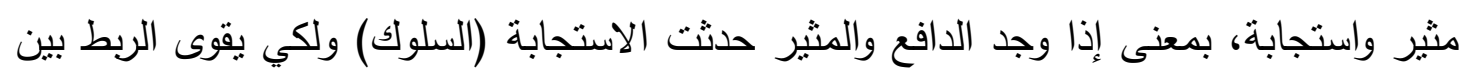

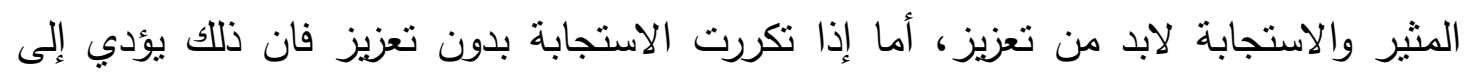

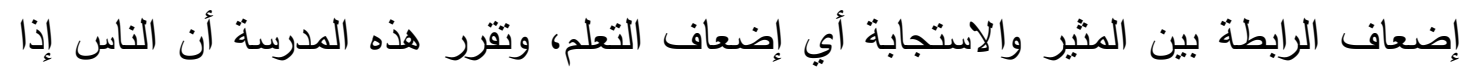

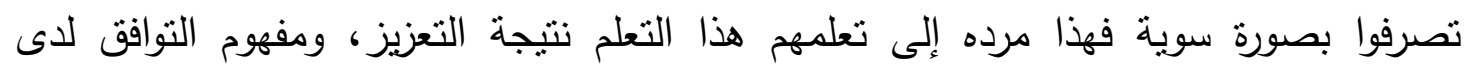
المدرسة السلوكية يتحدد باستجابات مناسبة للمثيرات المختلفة، بعيدا عن التوتر والقلق (العنابي،

$$
\text { . }(V \cdot \text {. r.... }
$$

ولهذا السبب فان أفضل الأساليب وصولا للتوافق النفسي والاجتماعي من وجهة النظر

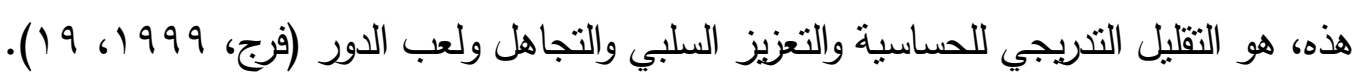
فترى المدرسة السلوكية على هذا الأساس انه يجب وصف الفئس الأشخاص على ولى أنهم كائنات

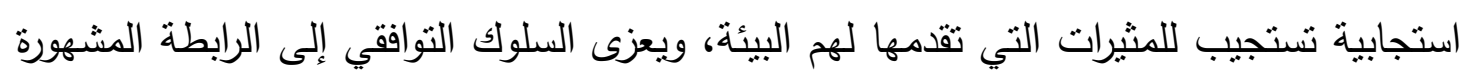

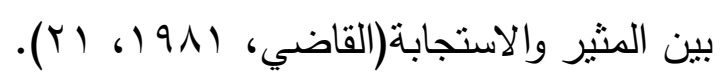

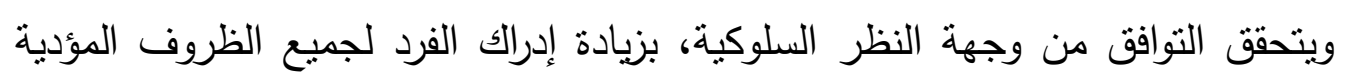

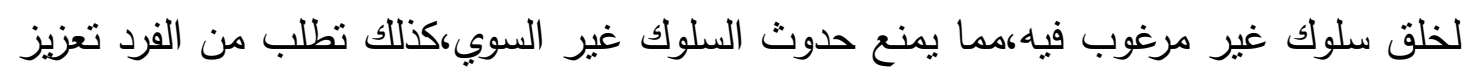

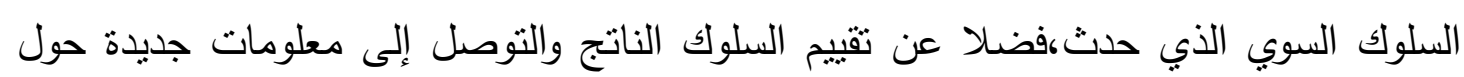

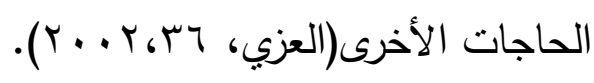

$$
\begin{aligned}
& \text { * النظرية الوجودية: }
\end{aligned}
$$

يتضمن مفهوم التوافق النفسي والاجتماعي من وجهة نظر أصحاب النظرية الوجودية،

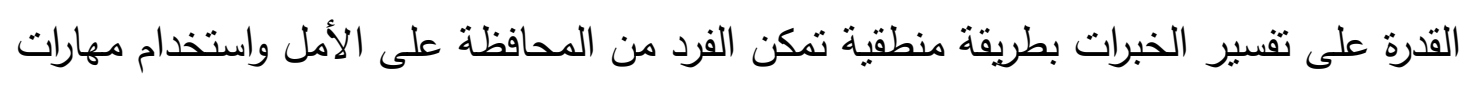

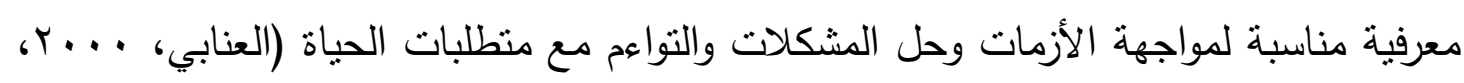

إذا فقد اهتمت هذه النظرية بدراسة جوهر الفرد وركزت على خبراته الثخصية بشكل

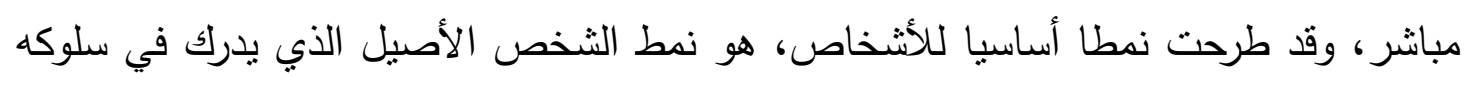

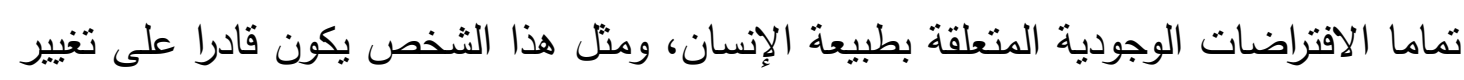

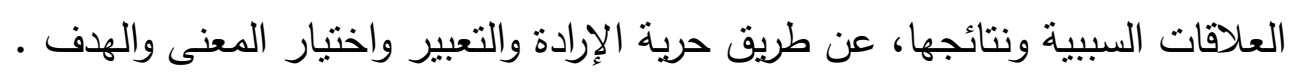

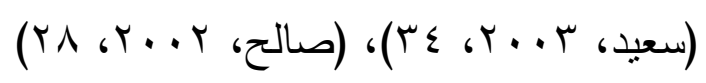




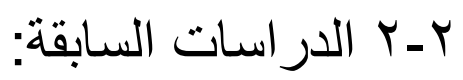

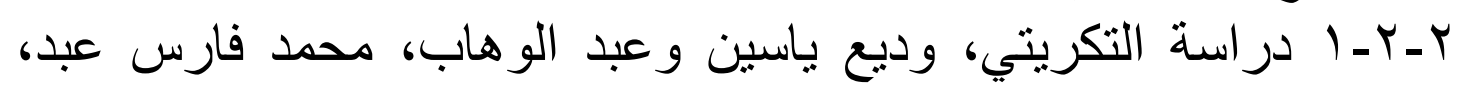
$: Y \cdot r$ "دراسة مقارنة في التوافق النفسي والاجتماعي بين طلاب جامعة الموصل الرياضيين وغير الرياضيين"

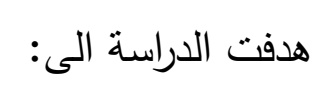

- تقويم التوافق النفسي والاجتماعي لدى طلاب جامعة الموصل من الرياضيين وغير الرياضيين.

- معرفة المواقف التوافقية الايجابية التي يتميز بها كل من الطلاب الرياضيين وغير الرياضيين.

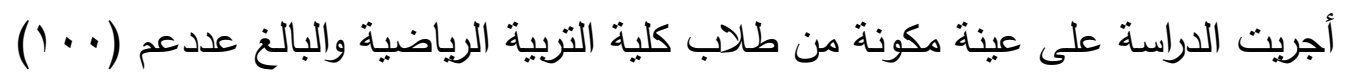

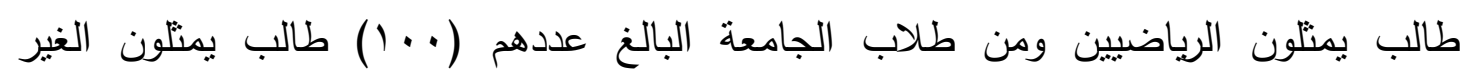

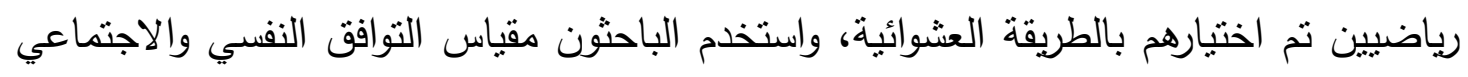

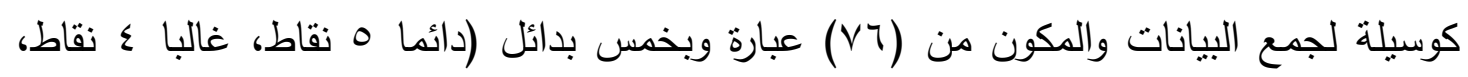

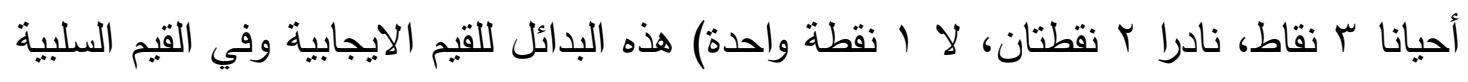

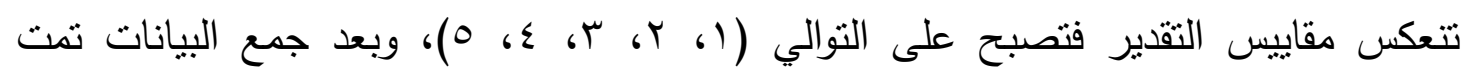

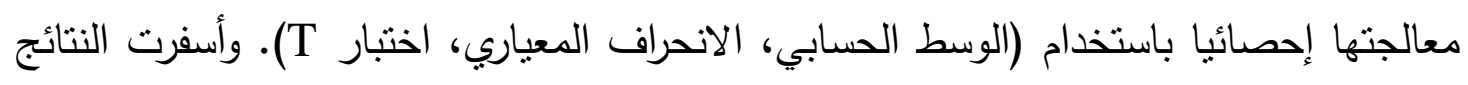
عن: - تفوق الرياضيين على غير الرياضيين من طلبة جامعة الموصل في التوافق النفسي

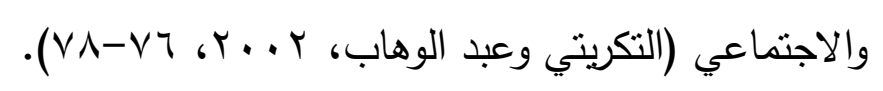

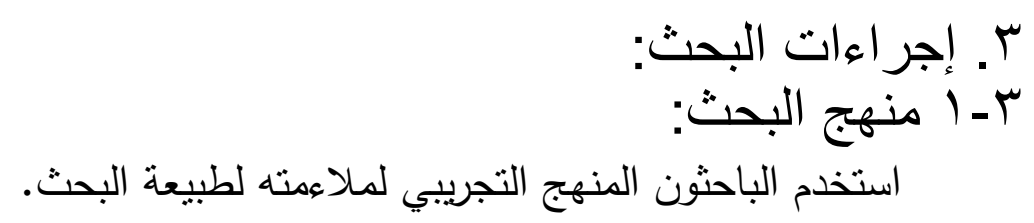
r-r r r r rتمع البحث و عينته: تكون مجتمع البحث من طلاب الصف الته الثاني متوسط في مدرسة ثانوية الحدباء

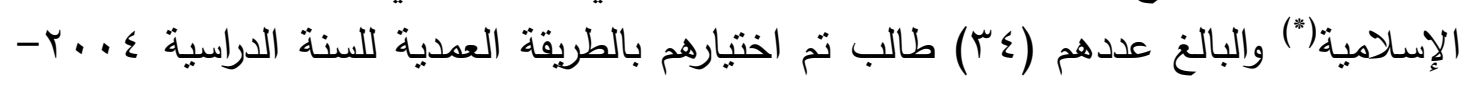

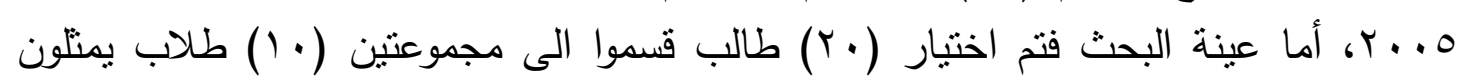

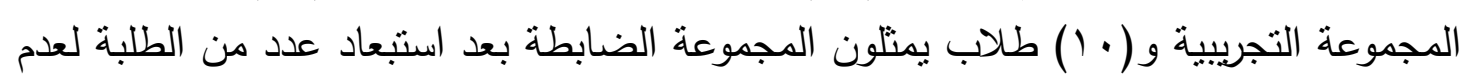

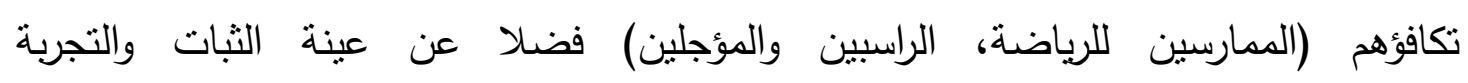
الاسنطلاعبة. 
r-r تجانس مجمو عتي البحث:

r-r-1 التجانس في الطول: مقاسا بالسنتمنز (تم حسابه لأقرب سنتمنر ).

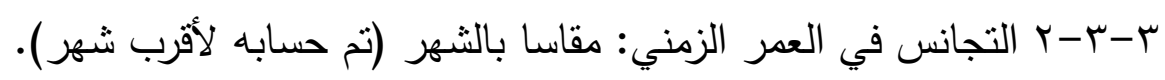

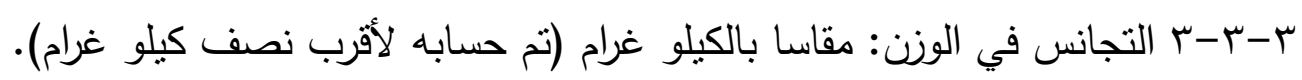

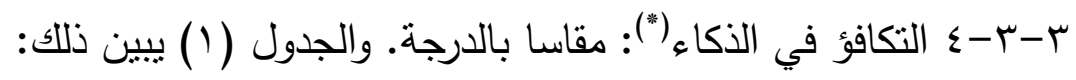

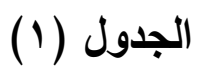

يبين المعلم الإحصائية وقيم (ت) المحسوية لتكافؤ المجموعتين التجريبية والضابطة في المتغيرات الطول والعمر والوزن والذكاء

\begin{tabular}{|c|c|c|c|c|c|c|}
\hline \multirow{2}{*}{ قليمة(ت) } & \multicolumn{2}{|c|}{ المجموعة الضابطة } & \multicolumn{2}{|c|}{ المجموعة التجريبية } & \multirow{2}{*}{ وحدة } & \multirow{2}{*}{ المتغيرات } \\
\hline & $\varepsilon^{ \pm}$ & س & $\varepsilon^{ \pm}$ & س & & \\
\hline$\cdot, 710$ & $V, 701$ & 107,577 & $\Lambda, 79 r$ & $10 \Lambda, \Lambda \varepsilon$ & سم & الطول \\
\hline 1,19 & T, Y & $177, \varepsilon$ & $r, Y, r$ & $17 \Lambda, 1$ & شهر & العمر \\
\hline דצ & $V, \wedge 9 Y$ & $0 \varepsilon, r$ & $\Lambda, r \leq T$ & OY,T & كغم & الوزن \\
\hline$\cdot, \vee 09$ & $\varepsilon, V \backslash 1$ & $\varepsilon r, 0$ & $7, r \leq 7$ & $\varepsilon \cdot, 0$ & درجة & الذكاء \\
\hline
\end{tabular}

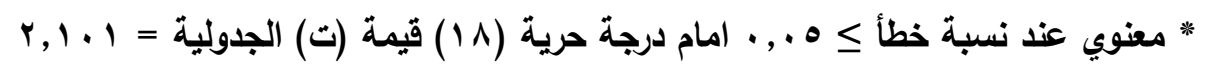

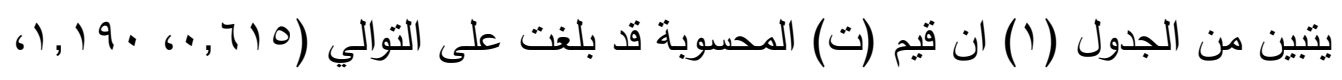

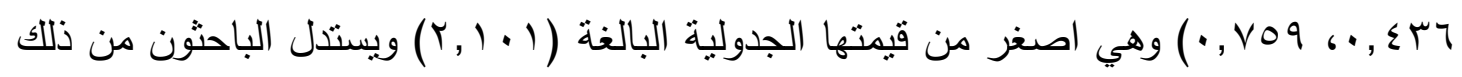

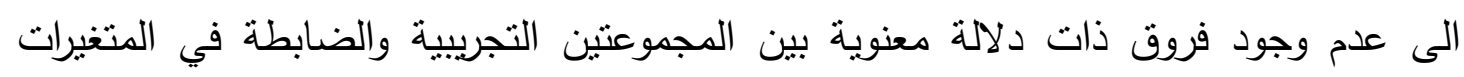
(الطول، العمر، الوزن، الذكاء) مما يشير الى تكافؤ المجموعتين بتلك المتغيرات.

ب-ع وسائل جمع البيانات: - استبيان التوافق النفسي والاجتماعي.

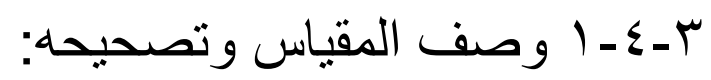

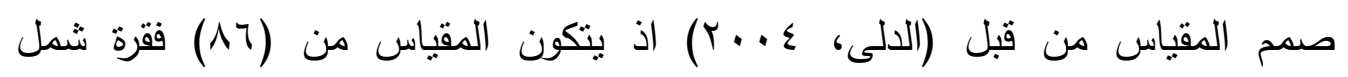

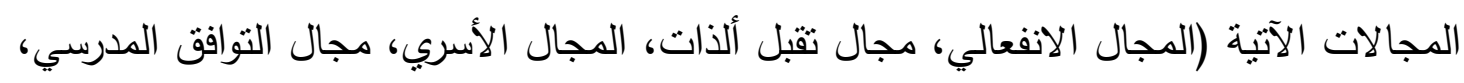

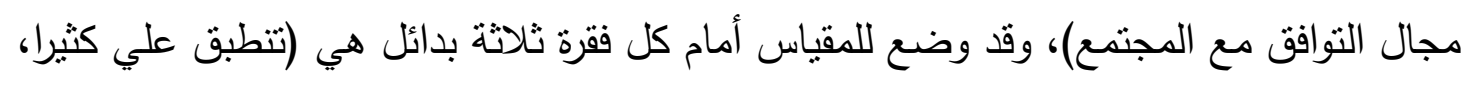
تتطبق أحيانا، لا تتطبق).

(") تم استخدام اختبار رافن للمصفوفات المتتابعة لقياس الذكاء الذي قننه للبيئة العراقية فخر الدين واخرون

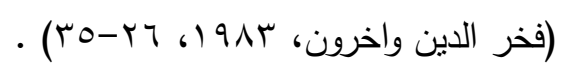


أما تصحيح المقياس فتم بإعطاء درجتين للبديل (تتطبق علي كثيرا)، ودرجة واحدة

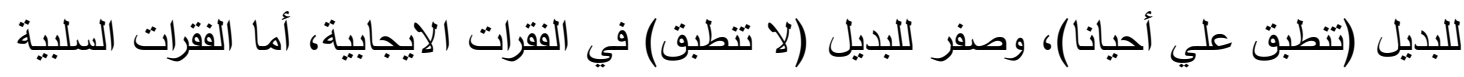
فقد تم إعطاء درجتين للبديل (لا تتطبق) ودرجة واحدة للبديل (تتطبق علي أحيانا) وصفر للبديل اللبديل

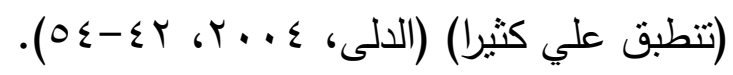

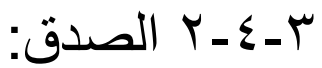
تم عرض الاختبار وفقراته على مجموعة من المختصين (") في مجال (طرائق التدريس،

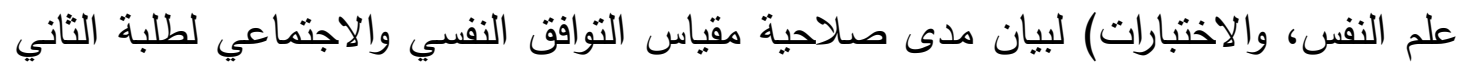

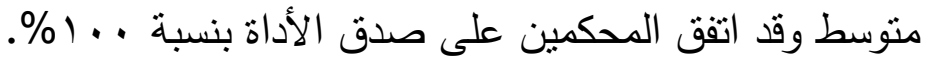

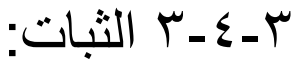

استخرج الباحثون الثبات بطريقة إعادة الاختبار على عينة مؤلفة من (0) طلاب من

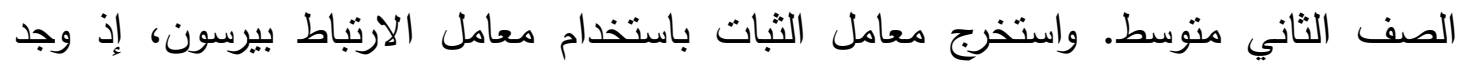

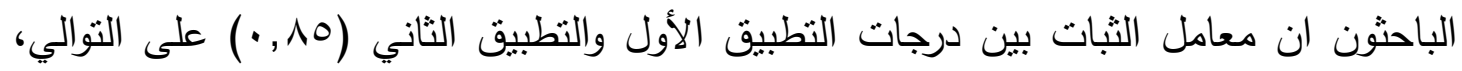
وهي مؤشرات تدل على ثبات جيد للاختبار .

$$
\begin{aligned}
& \text { بـه الأدوات المساعدة المستخدمة في البحث: }
\end{aligned}
$$

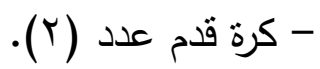

$$
\begin{aligned}
& \text { - كرة سلة عدد (Y) كرة (Y). } \\
& \text { - كرة طائرة عدد (Y) كرة علد (Y). }
\end{aligned}
$$

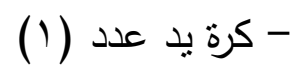

$$
\begin{aligned}
& \text { - ساعة نوقيت عدد (1) (1) - (1) - }
\end{aligned}
$$

( أسماء المختصين: ( )

- أ. أنتيبة زكي التثل/ كلية التزبية الرياضية/ جامعة الموصل.

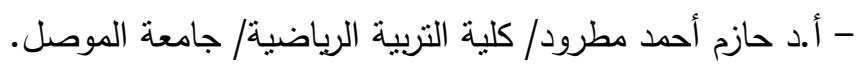

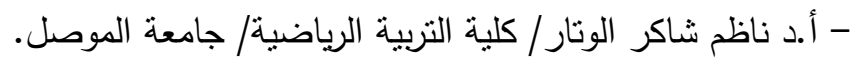

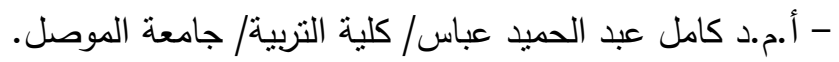

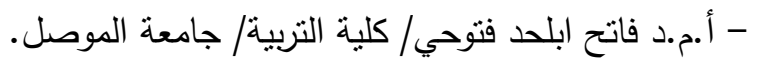

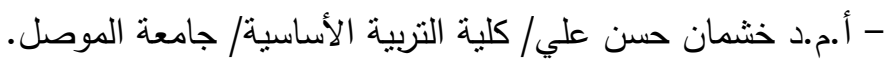

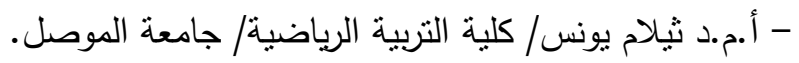

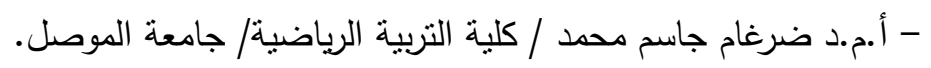

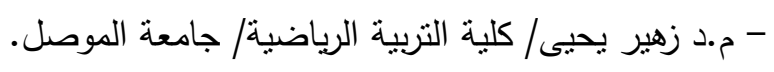


ب-7 التصميم التجريبي:

استخدم الباحثون التصميم التجريبي الذي يطلق عليه اسم (تصميم المجموعتين

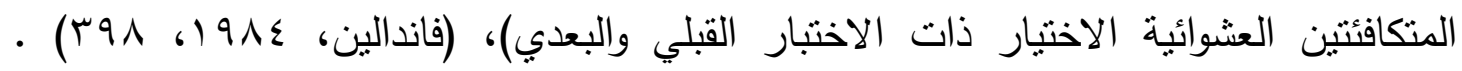
ويمكن تمثيل هذا التصميم على النحو الأتي:

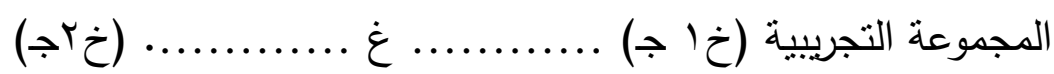

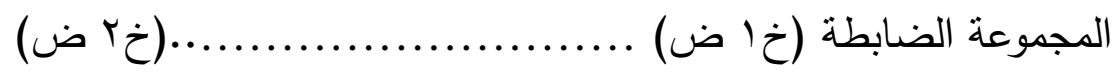

(ب) الثكل (ب)

يوضح التصميم التجريبي للبحث

اذ ان الرموز الواردة في التصميم تدل على ما يأني:

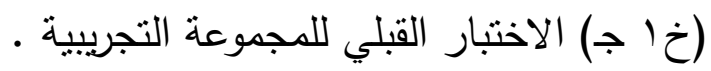

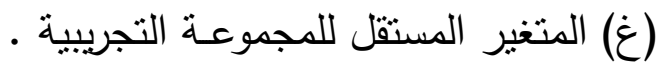

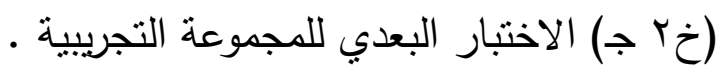

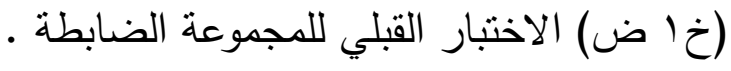

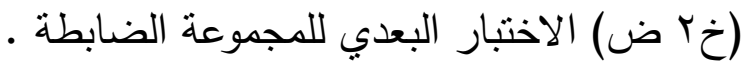

س- المنهاج التعليمي للرس التربية الرياضية المستخدم في البحث:

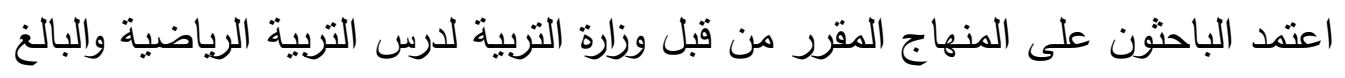
مدته (0؛) دقيقة لدرس الواحد لغرض تطبيقه على الدجموعة التجريبية والذي شمل على فعاليات

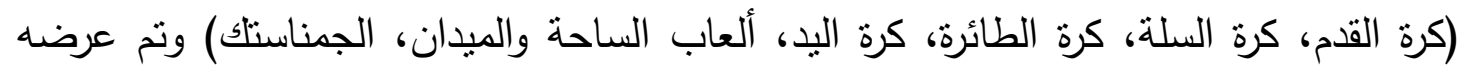
على مجموعة من المختصين (") وقد نم الاتفاق عليه بنسبة (†^\%) واستبعاد عدد من الفعاليات

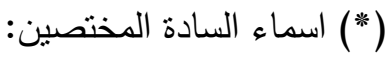

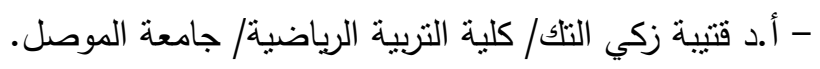

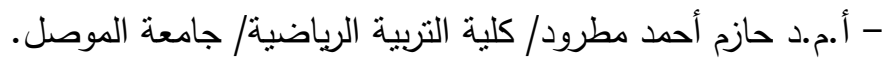

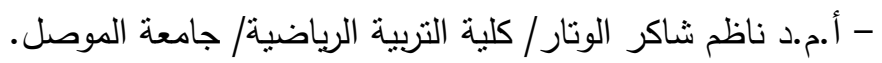

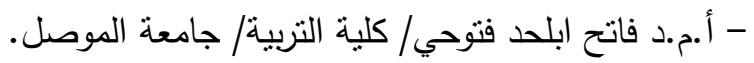

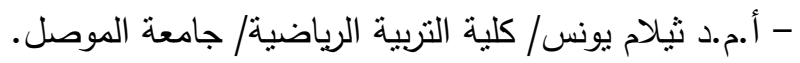

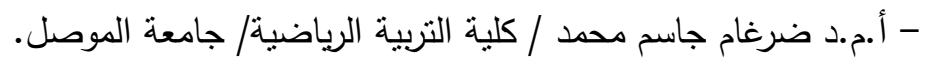
- م.د زهير يحيى/ كلية التربية الرياضية/ جامعة الموصل. 
(الجمناستك، وألعاب الساحة والميدان) لعدم توفر الأدوات ألازمة لنطبيقها وبموافقة الخبراء أيضا

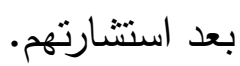

r-V-1 - البرنامج التعليمي لدرس التربية الرياضية:

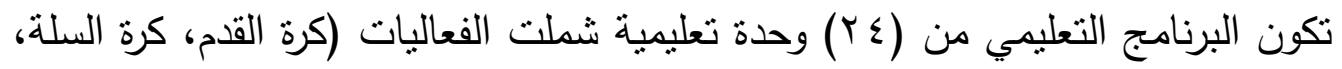

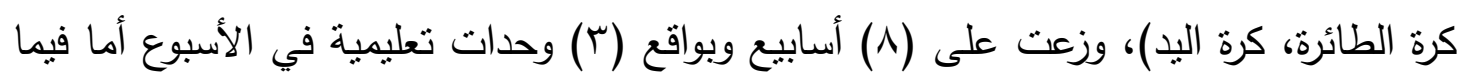

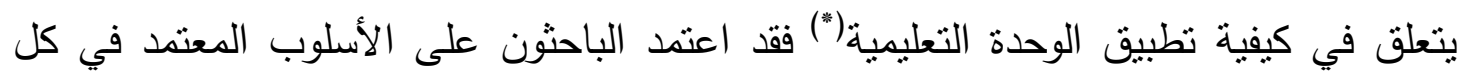

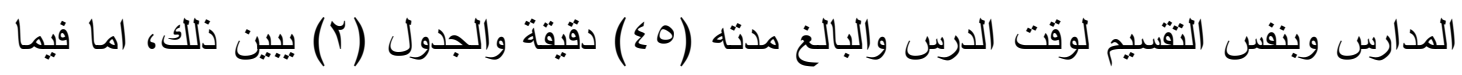

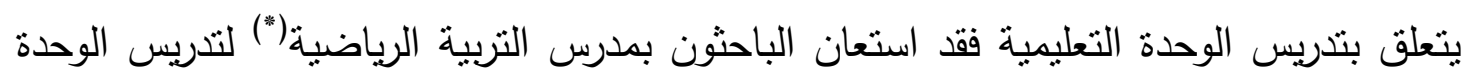
التعليمية كما استعان الباحثون بملعب(") نادي الفتوة الرياضي كمكان لتدريس الوحدة التعليمية.

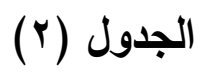

يبين التقسيم الزمني لأجزاء الوحدة التعليمية

\begin{tabular}{|c|c|c|}
\hline النسبة المئوية & الزمن & الجزيع \\
\hline 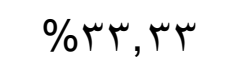 & 210 & ا ـ الجزع الإعدادي \\
\hline$\% 11,11$ & Oد & أ- المقدمة (النشاط التتظيمي والإداري) \\
\hline$\% 11,11$ & Oد & ب- الإحماء (الإعداد العام) \\
\hline$\% 11,11$ & مد & ج- التمرينات البدنية (الإعداد الخاص) \\
\hline$\% 00,00$ & د & r ـ الجزء الرئيسي \\
\hline$\% 10,00$ & $د V$ & أ- النشاط التعليمي \\
\hline$\% \leq$ & 211 & ب- النشاط النطبيقي \\
\hline$\% 11,11$ & هد & r. الجزء الختامي \\
\hline
\end{tabular}

(") انظر الملحق (؟).

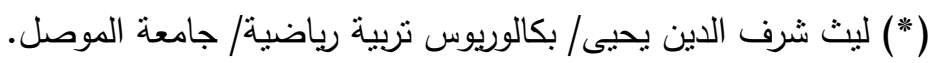

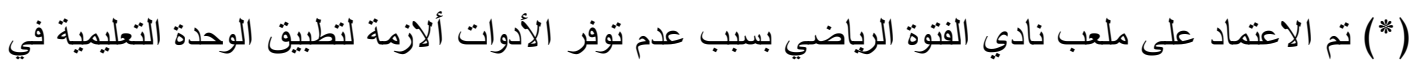
الدرسة فضلا عن قرب الملعب من المدرسة. 
م-1 التجربة الاستطلاعية: قام الباحثون ومدرس المادة بإجراء التجربة الاستطلاعية لأداة البحث بتاريخ

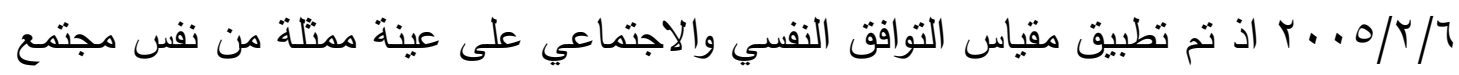
الدراسة والبالغ عددهم (0) طلاب بهدف الكثف عن مدى ملائمة ووضوح فقرات المقياس لمستوى عينة البحث.

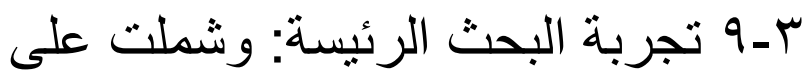

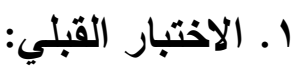

تم إجراء الاختبار القبلي لمقياس التوافق النفسي والاجتماعي على مجموعتي الدراسة

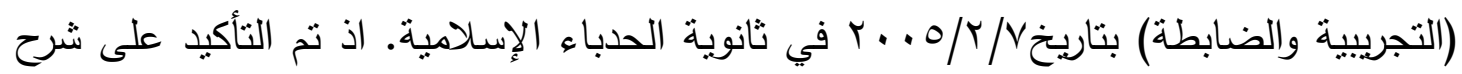

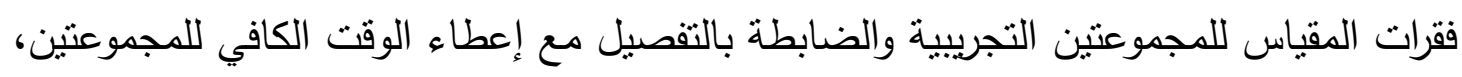
والجدول (r) يبين ذلك

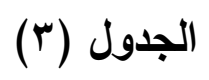

يبين المعالم الإحصائية وقيم (ت) المحسوية للاختبار القبلي بين المجموعتين التجريبية

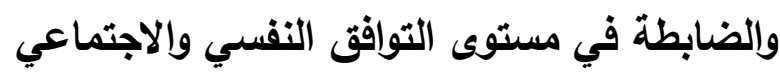

\begin{tabular}{|c|c|c|c|c|c|}
\hline \multirow{2}{*}{ قايمة (ت) } & \multicolumn{2}{|c|}{ المجموعة الضابطة } & \multicolumn{2}{|c|}{ المجموعة التجريبية } & \multirow{2}{*}{ المتغير } \\
\hline & $\varepsilon^{ \pm}$ & س - - - مس & $\varepsilon^{ \pm}$ & س & \\
\hline$\cdot, 017$ & $11, \varepsilon$ & $1 \cdot r, \varepsilon$ & 9,19 & $99, \wedge$ & التوافق النفسي والاجتماعي \\
\hline
\end{tabular}

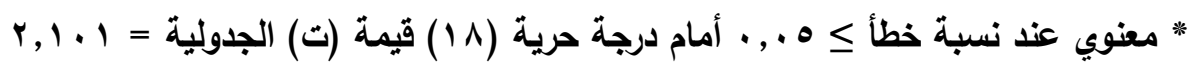

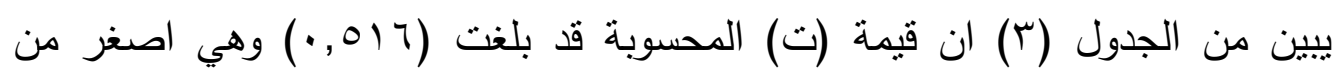

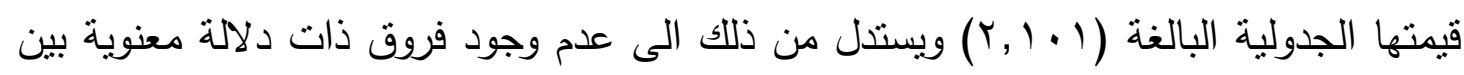
المجموعنين التجريبية والضابطة في مستوى التوافق النفسي والاجتماعي، مما يشير الى تكافؤ

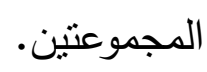

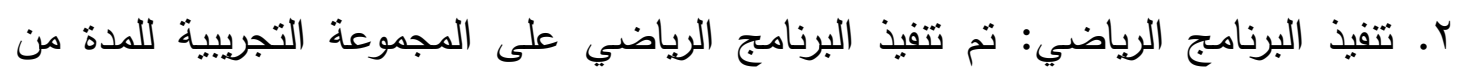

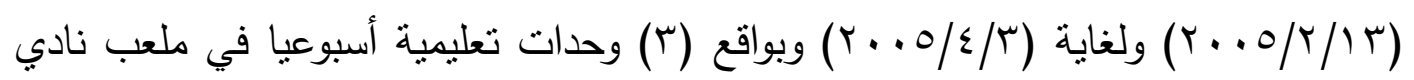
الفتوة الرياضي.

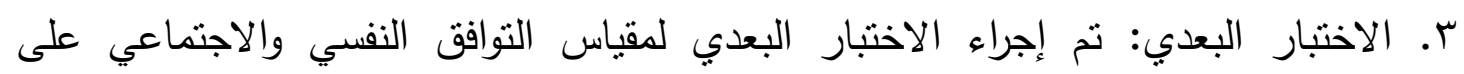

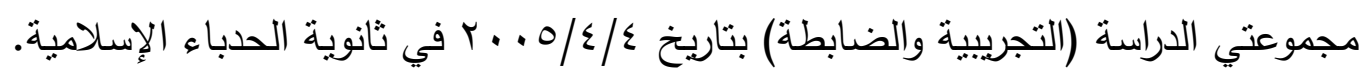




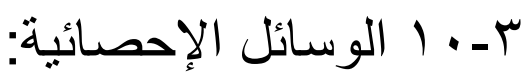

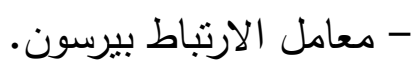

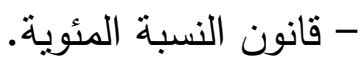

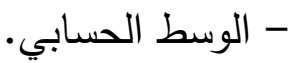

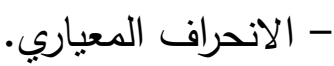

- اختبار (ت) لوسطين حسابيين مرتبطين متساويين العدد.

- اختبار (ت) لوسطين حسابيين غير مرتبطين متساويين العدد منين العنين

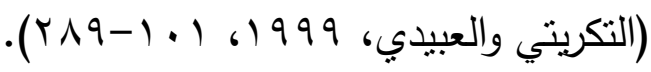

ع. عرض النتائج ومناقشتها:

ـ ـ البعرض علتائج التوافق النفسي والاجنماعي بين الاختبارين القبلي و البعدي للمجموعة التجريبية ومناقشتها:

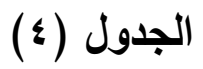

يبين المعالم الإحصائية وقيم (ت) المحسوية للاختبارين القبلي والبعدي في مستوى التوافق النفسي والاجتماعي للمجموعة التجريبية النائية

\begin{tabular}{|c|c|c|c|c|c|}
\hline \multirow{2}{*}{ قالمحسوية } & \multicolumn{2}{|c|}{ الاختبار البعدي } & \multicolumn{2}{|c|}{ الاختبار القبلي } & \multirow{2}{*}{ المتغير } \\
\hline & $\varepsilon^{ \pm}$ & س & $\varepsilon^{ \pm}$ & س - س & \\
\hline *Ir,,$Y \vee \wedge$ & $q, 1 r$ & $1 \leqslant 7, r$ & $9, \wedge 9$ & $99, \wedge$ & التوافق النفسي والاجتماعي \\
\hline
\end{tabular}

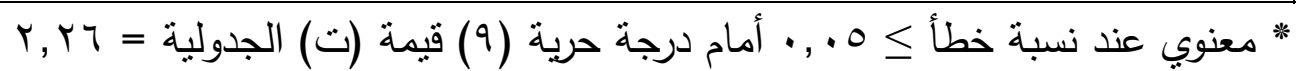

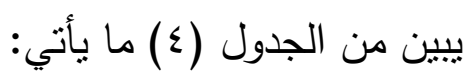

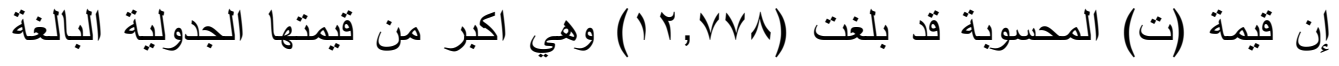

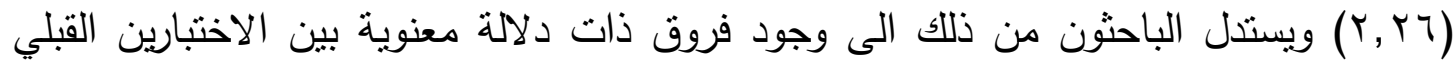

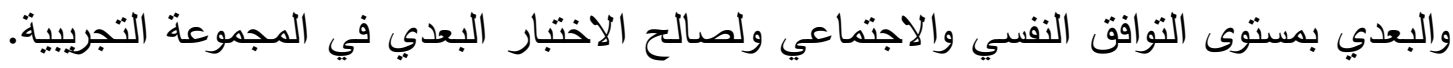

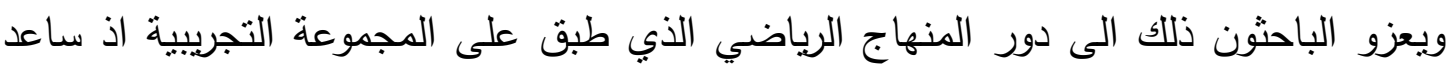

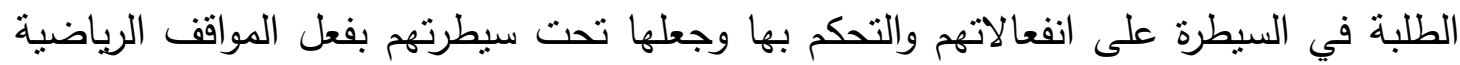

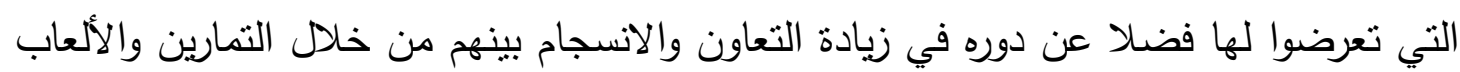

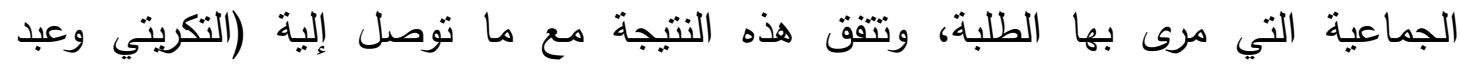

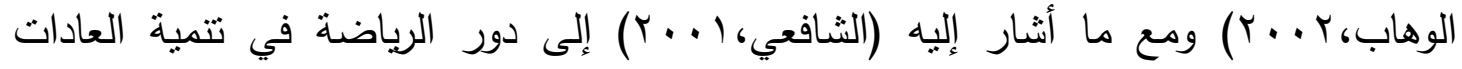

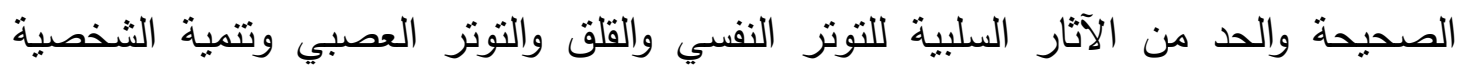

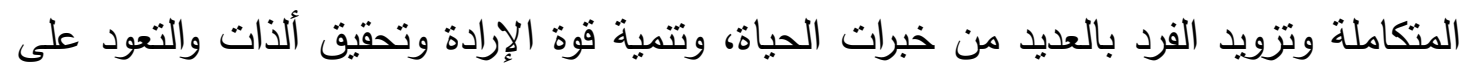

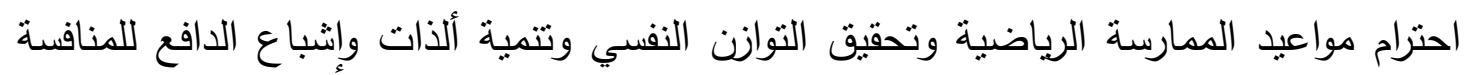

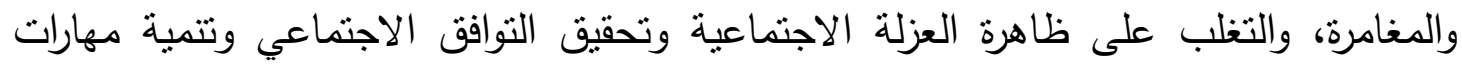

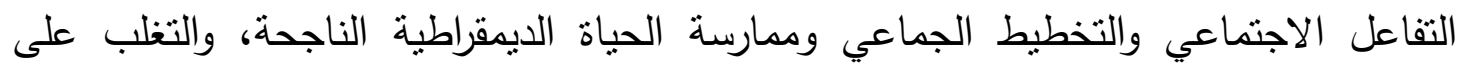


الأسلوب التقليدي للحياة وزيادة البهجة والسعادة وزيادة القدرة على مواجهة الحياة (التكريتي وعبد

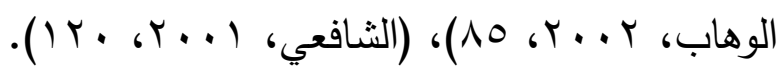

ع - Y عرض نتائج التوافق النفسي والاجتماعي بين الاختبارين القبلي و البعدي للمجمو عة الضابطة ومناقشتها:

(0) الجدول

يبين المعالم الإحصائية وقيم (ت) المحسوية للاختبارين القبلي والبعدي في مستوى التوافق النفسي والاجتماعي للمجموعة الضابطة التهية

\begin{tabular}{|c|c|c|c|c|c|}
\hline \multirow{2}{*}{ قالمحسوية } & \multicolumn{2}{|c|}{ الاختبار البعدي } & \multicolumn{2}{|c|}{ الاختبار القبلي } & \multirow{2}{*}{ المتغير } \\
\hline & $\varepsilon^{ \pm}$ & س & $\varepsilon^{ \pm}$ & س & \\
\hline 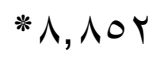 & 11,0 & IrA & $11, \varepsilon$ & $1 \cdot r, \varepsilon$ & التوافق النفسي والاجتماعي \\
\hline
\end{tabular}

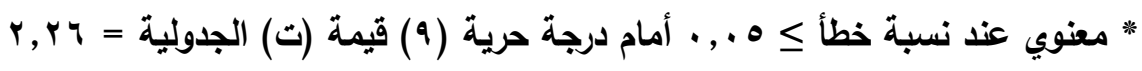

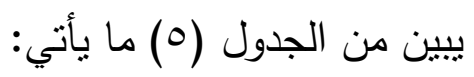

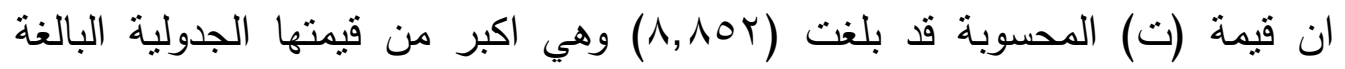
(Y, Y (T) ويستدل الباحثون من ذللك الى وجود فروق ذات دلالة معنوية بين الاختبارين القبلي والبعدي بمستوى التوافق النفسي والاجتماعي ولصالح الاختبار البعدي في المجموعة الضابطة.

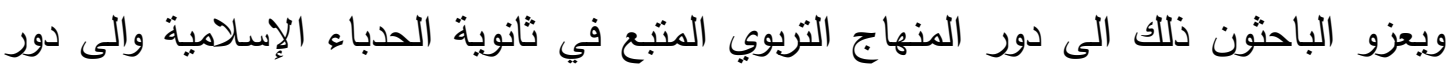
مدرسي الثانوية في تفعيل دور الطالب دمع المادة ومع زملاءه.

ع - ع عرض نتائج التوافق النفسي والاجتماعي للمجموعتين التجريبية و الضابطة في الاختبار البعدي ومناقثتنها:

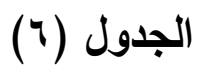

يبين المعالم الإحصائية وقيم (ت) المحسوية للاختبار البعدي بين المجموعتين التجريبية والضابطة في مستوى التوافق النفسي والاجتماعي

\begin{tabular}{|c|c|c|c|c|c|}
\hline \multirow{2}{*}{ قيمة المحسوبة } & \multicolumn{2}{|c|}{ المجموعة الضابطة } & \multicolumn{2}{|c|}{ المجموعة التجريبية } & \multirow{2}{*}{ المتغير } \\
\hline & $\varepsilon \pm$ & س & $\varepsilon^{ \pm}$ & س & \\
\hline$\varepsilon, 19$ & 11,0 & IrA & $9,1 r$ & $1 \leq 7, r$ & التوافق النفسي والاجتماعي \\
\hline
\end{tabular}

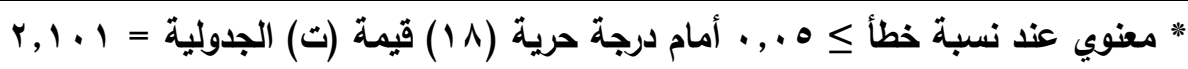




$$
\text { بيين من الجدول (؟) ما يأني: }
$$

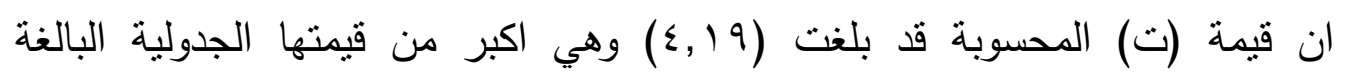

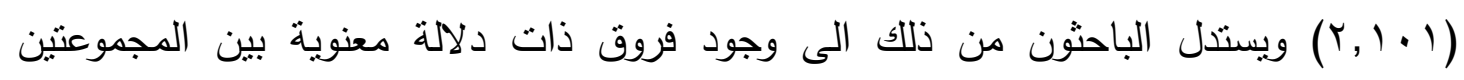

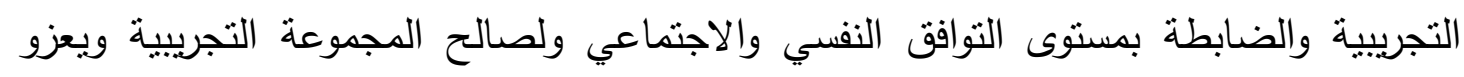

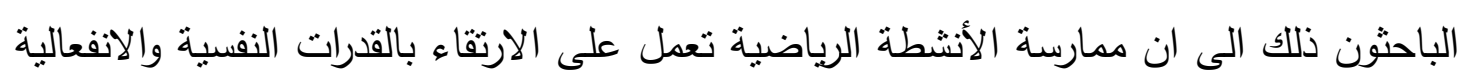

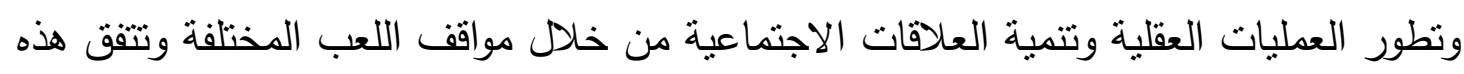

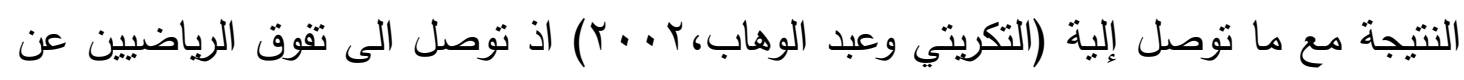

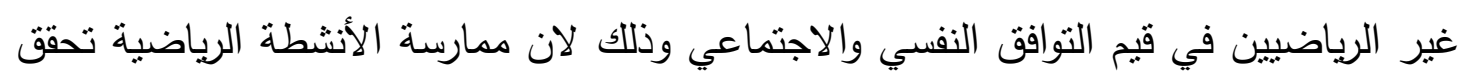

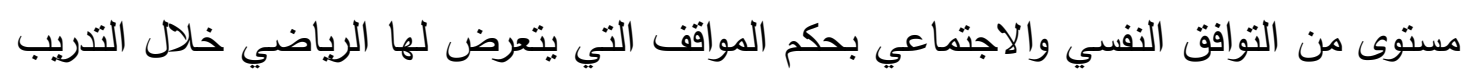

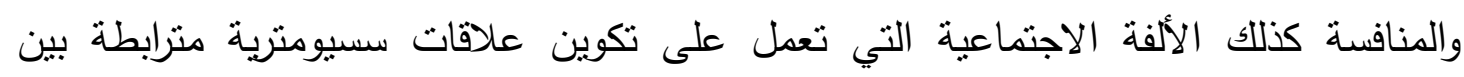

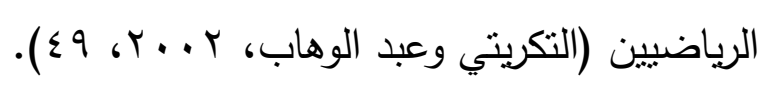

\section{0 - الاستنتاجات و التوصيات: 0ـ - الاستنتاجات:}

0-1-1 اثثت المنهاج الرياضي فاعليته في تطوير مستوى التوافق النفسي والاجتماعي لطلاب الناب الثاني متوسط في ثانوية الحدباء الإسلامية.

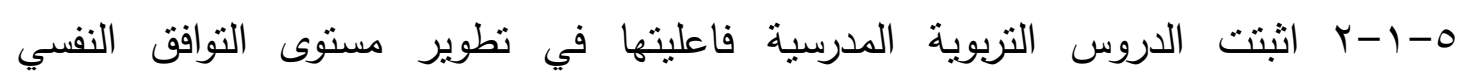
والاجتماعي لطلاب الثاني متوسط في ثانوية الحدباء الإسلامية.

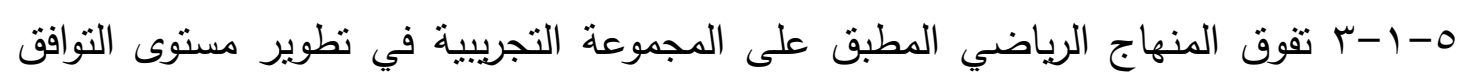
النفسي والاجتماعي عند مقارنته بالمجموعة الضابطة في الاختبار البعدي.

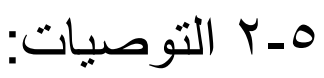

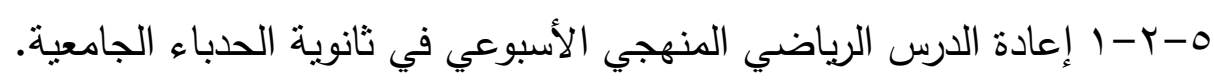

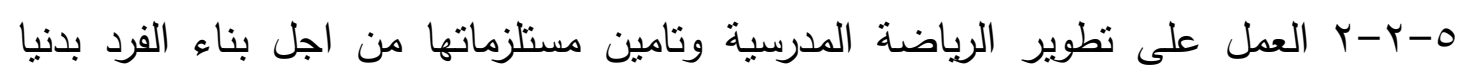
ونفسيا واجتماعيا.

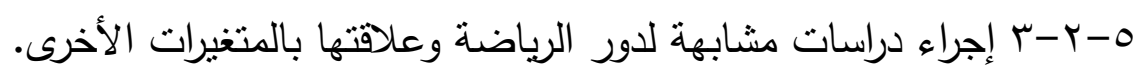




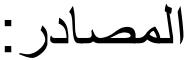

1. التكريتي، وديع ياسين والعبيدي، حسن محمد (999 (1): التطبيقات الإحصائية واستخدامات

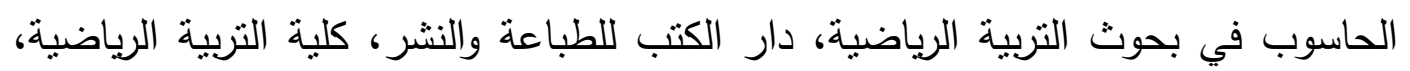

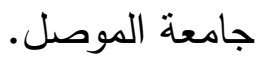

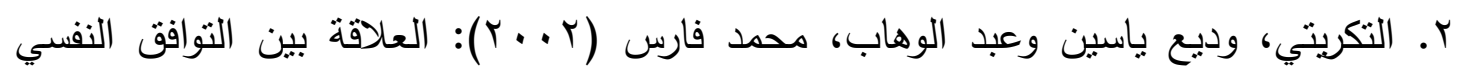
والاجتماعي والسلوك الايثاري لدى الرياضيين وغير الرياضيين من طلاب جامعة الموصل، الرابل

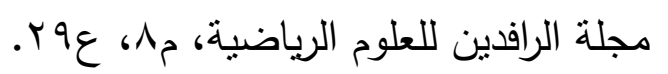

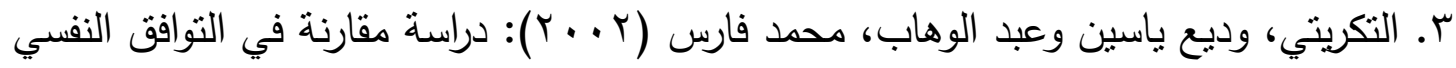
والاجتماعي بين طلاب جامعة الموصل الرياضيين وغير الرياضيين، مجلة الرافدين للعلوم

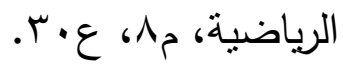

ع. الخولي، وليم (ج/9V1): الموسوعة المختصرة في علم النفس والطب العقلي، دار المعارف،

0. داؤد، عزيز حنا والعبيدي، ناظم هاشم (.99 (1): علم نفس الثخصية، دار الكتب للطباعة،

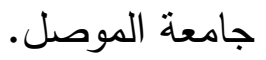
T. الداهري، صالح حسن احد (1) (ب): مشكلات الطلبة في المرحلة الإعدادية وحاجاتهم

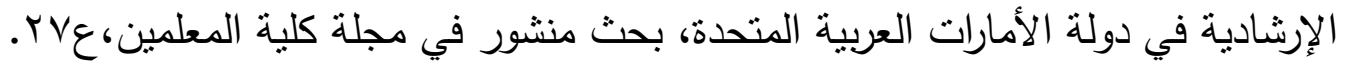

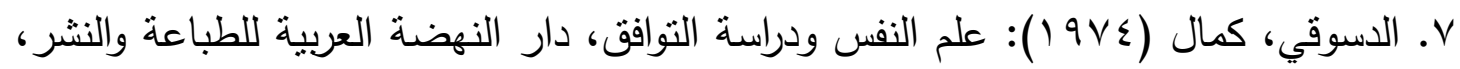
بيروت.

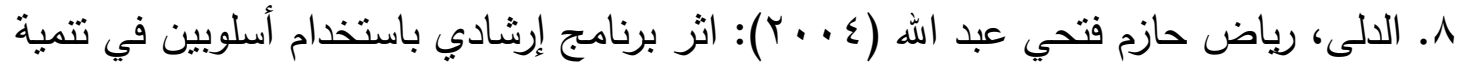

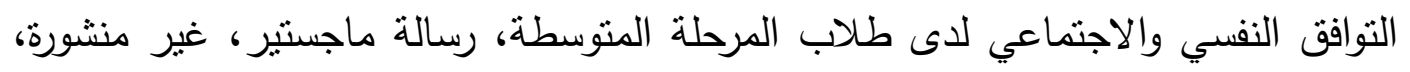
كلية التزبية، جامعة الموصل.

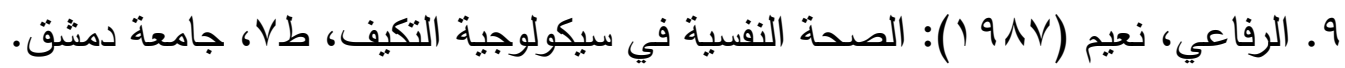

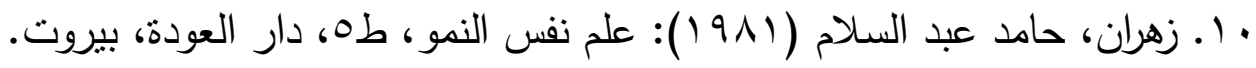
(1 ـ زهران، حامد عبد السلام (911 (1):الصحة النفسية والعلاج النفسي، دار المعارف، القاهرة.

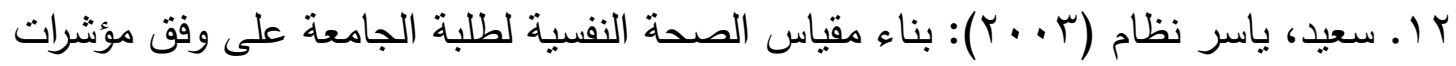
مقياس منيسوتا المتعدد الأوجه M.M.I. أطروحة دكتوراه، غير منشورة، كلية التربية،

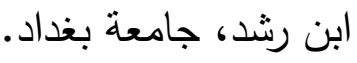

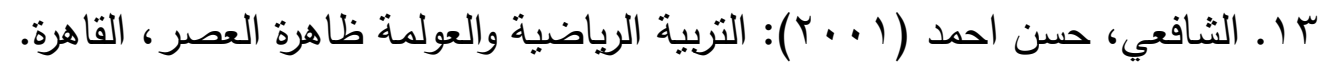
ـ ا ـ الثرقاوي، دصطفى خليل (r/91 (): علم الصحة النفسية، دار النهضة العربية، بيروت. 
1 ـ الثمري، محمود رحيم جاسم (99V (1)): دراسة مقارنة في التحصيل الدراسي والتوافق النفس

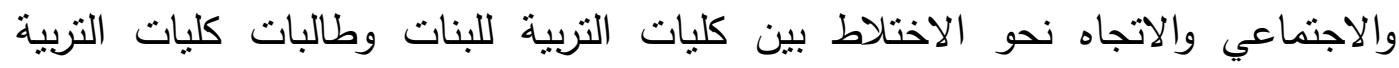

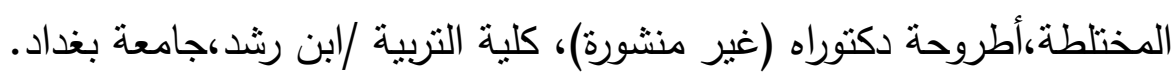

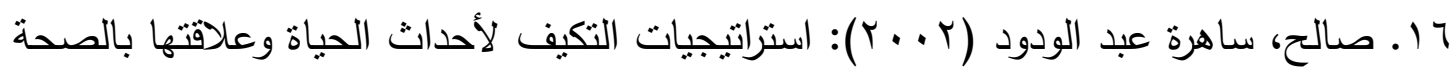
النفسية لطلبة الجامعة، أطروحة دكتوراه، غير منشورة، كلية التربية، جامعة بغداد.

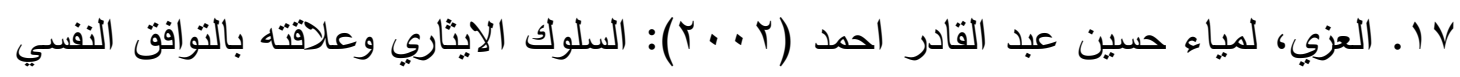
والاجتماعي ومفهوم ألذات لاى طلبة جامعة الموصل،رسالة ماجسنير (غير منشورة)، كلية

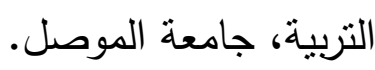

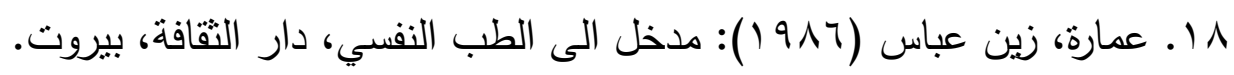

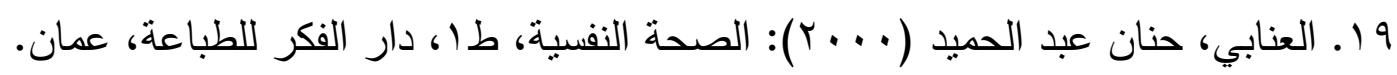

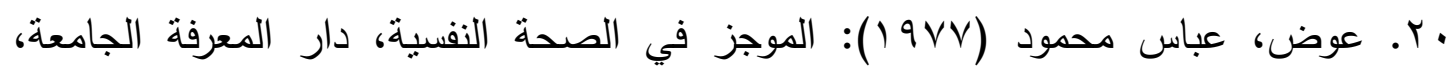
الإسكندرية. (Y. فرج، كاملة وتيم عبد الجبار (999 (1):الصحة النفسية للطفل، دار صفاء للنشر والتوزيع،

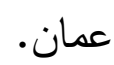

r r r فهي، مصطفى(9V9 (1)): التوافق الثخصي والاجتماعي، مكتبة الانجلو، القاهرة.

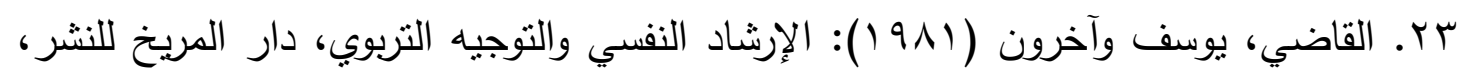

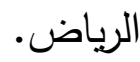

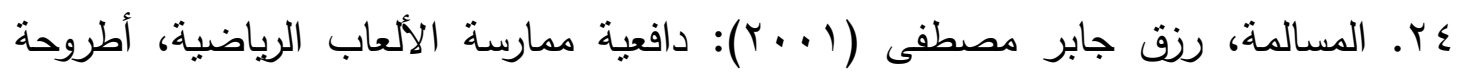

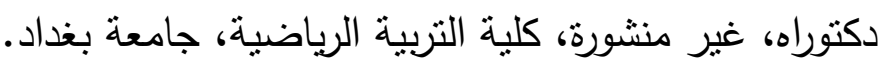




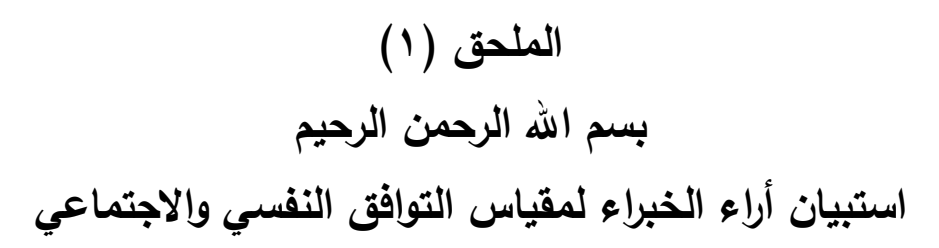

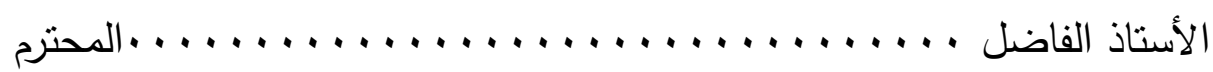

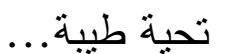

يروم الباحثون إجراء دراسة لمعرفة (اثرالمنهاج التعليمي لدرس التربية الرباضية في تتمية التوافق النفسي والاجتماعي لدى طلبة الصف الثاني متوسط).

وقد استعان الباحثون بمقياس التوافق النفسي والاجتماعي المعد من قبل (رباض حازم

فتحي،ء . . r) والذي يتضمن ثناث بـائل وهي (تتطبق علي كثيرا، تتطبق علي أحيانا، لا

تتطبق)

ويقصد بالتوافق النفسي والاجتماعي: بانه عملية تعديل الفرد بناءه النفسي او سلوكه،

ليستجيب لنشروط المحيط الطبيعي والاجتماعي ويحقق لنفسه الثعور بالتوازن والرضا.

ونظرا لما تتمتعون بـه من خبرة ودراية يسر الباحثون أن يعرضوا عليكم الفقرات آلاتية

لبيان رأيكم حول مدى صلاحيتها ووضوحها وتكرارها وإمكانية دمجها، واقتراح التعديل المناسب.

$$
\text { ولكم فائق التقدير والاحترام }
$$

$$
\text { الالاختم واللقب العلمي: الباصنيع: }
$$


مقياس التوافق النفسي والاجتماعي (بصيغته الأولية والنهائية)

\begin{tabular}{|c|c|c|c|c|}
\hline ل ل التطبق & تنطبق علي & تنطبق علي & 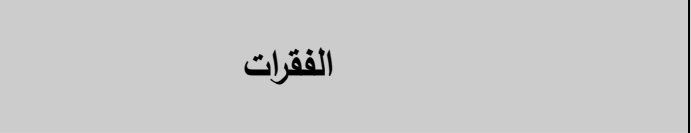 & $ت$ \\
\hline & & & اشعر بالخوف في مواقف يعتبرها أقراني طبيعية & 1 \\
\hline & & & اقلق إزاء أمور بسيطة & r \\
\hline & & & ا اشعر باني سريع الغضب & r \\
\hline & & & | يزعجني شعوري بالخجل & $\varepsilon$ \\
\hline & & & اعبر عن فرحي بطريقة قد يرفضها الآخرون & 0 \\
\hline & & & أحس باني إنسان مرح & 7 \\
\hline & & & احترم التقاليد حتى وان كانت ضد ما ارغب به & v \\
\hline & & & أتخيل تحقيق الأهداف عندما لا أستطيع تحقيقها & $\wedge$ \\
\hline & & & |برر أخطائي وان كنت واتقا من خطئي & 9 \\
\hline & & & أنمسك بآرائي بشدة وان كنت غير واثق من صحتها & 1. \\
\hline & & & | أعاني من عدم التركيز والثرود الذهني & 11 \\
\hline & & & أحب الوحدة وعدم الاختلاط & ir \\
\hline & & & اشتعر أنني سعيد في حياتي & 14 \\
\hline & & & اشعر أن الآخرين يحبونني & $1 \leq$ \\
\hline & & & أحب الناس & 10 \\
\hline & & & أنقبل الصفات الثخصية التي امتلكها & 17 \\
\hline & & & أثق بنفسي & iv \\
\hline & & & اشتعر باحترامي لنفسي & 11 \\
\hline & & & أحس بان الغرور يتملكني & 19 \\
\hline & & & اعتقد أنني إنسان ذو إرادة قوية & $r \cdot$ \\
\hline & & & |شعر بالنقص في بعض جوانب شخصيتي & Y \\
\hline & & & أحس بأنني إنسان صريح & rt \\
\hline & & & اشعر بأنني إنسان مهم بين الآخرين & rt \\
\hline & & & أحس أن الآخرين بعتمدون علي & $r \leq$ \\
\hline & & & اندم على خطئي إذا ما شعرت به & ro \\
\hline & & & استقيد من أخطائي عندما أتأكد منها & rt \\
\hline & & & اشعر أن لدي القدرة على تحقيق كل ما اطمح أليه & rV \\
\hline & & & احل مشكلاتي أواجهها دون خوف & r^ \\
\hline & & & اضطر للكذب تجنبا للمشاكل & rq \\
\hline & & & اعتد على نفسي في اغلب الأمور & r. \\
\hline
\end{tabular}




\begin{tabular}{|c|c|c|c|c|}
\hline 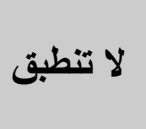 & تنطيق علي & تنطبق علي & 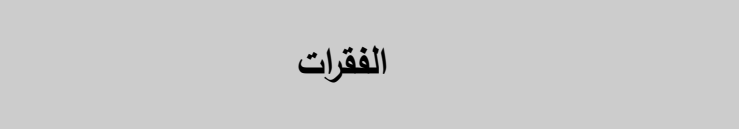 & $ت$ \\
\hline & & & لا يعجبني شعري & 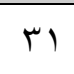 \\
\hline & & & أحس بان شكلي جميل & rr \\
\hline & & & أتنسامح مع الآخرين أتعاطف & r \\
\hline & & & يحاول الآخرون إثارة غضبي & $r \varepsilon$ \\
\hline & & & أحس بأنني مندمج مع العالم & ro \\
\hline & & & ارتبك عندما ينتقدني الآخرون & $r 4$ \\
\hline & & & اشعر بان الناس من حولي خيرون & rv \\
\hline & & & يثق بي أصدقائي & ru \\
\hline & & & استقيد من انتقادات الآخرين & rq \\
\hline & & & عندما أود تحقيق رغباتي اخذ بنظر الاعتبار رغبات الآخرين & $\varepsilon$ \\
\hline & & & اشعر وكان بعض الناس يراقبونني & $\varepsilon$ \\
\hline & & & استخدم حاجات الآخرين دون استئذان & $\varepsilon r$ \\
\hline & & & أتباهى بأنني انتمي للمجتمع الذي أنا فيه & $\varepsilon r$ \\
\hline & & & أششارك الآخرين أحزانهم & $\varepsilon \varepsilon$ \\
\hline & & & أنبادل الزيارات مع أصدقائي & «o \\
\hline & & & أثنارك الناس أفراحهم & $\varepsilon 7$ \\
\hline & & & اقدم المساعدة لمن يحتاجها & $\varepsilon V$ \\
\hline & & & تفهم أسرتي مشاعري وتحبني & $\varepsilon \wedge$ \\
\hline & & & أظن أن ثقة أسرتي بي ضعيفة & $\leq 9$ \\
\hline & & & أحس أن الآخرين يعجبه الحديث معي & 0. \\
\hline & & & لا توفر أسرتي لي الجو المناسب للاراسة & 01 \\
\hline & & & علاقتي جيدة بوالدي & or \\
\hline & & & أثق بأسرتي & or \\
\hline & & & احب المناقثات والاجتماعات العائلية & $0 \leqslant$ \\
\hline & & & انزعج كثيرا عند لوم أسرتي لي & 00 \\
\hline & & & ترفض أسرتي أصدقائي & 07 \\
\hline & & & اشعر بأهمية إرشادات أهلي & or \\
\hline & & & أسرتي تحاول مساعدتي في حل مشاكلي & 01 \\
\hline & & & اشعر أن أسرتي تتباهى بي & 89 \\
\hline & & & تقوم علاقتي بأهلي على الصراحة & 7. \\
\hline & & & أضحى من اجل أسرتي & $\pi$ \\
\hline & & & إذا واجهت أسرتي عقبة نتعاون في حلها & $4 \pi$ \\
\hline
\end{tabular}




\begin{tabular}{|c|c|c|c|c|}
\hline لا تلطبق & تنطبق علي & تنطبق علي & 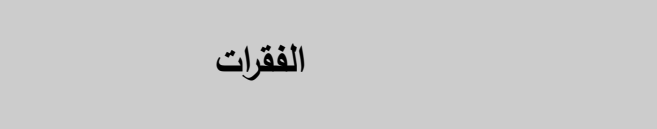 & ت \\
\hline & & & اشعر بالانزعاج من تقيبد حريتي في البيت & r \\
\hline & & & لا أحب طريقة والداي في التعامل معي & $7 \varepsilon$ \\
\hline & & & أتباهى بعلاقة أسرتي الطيبة معي & 70 \\
\hline & & & أساعد أخوتي في ترتيب المنزل & 77 \\
\hline & & & بزعجني بقائي في البيت فترة طويلة & TV \\
\hline & & & يفهم زملائي مشاعري & 11 \\
\hline & & & لتحقيق بعض ما ارغب به أخالف أنظمة المدرسة & 79 \\
\hline & & & أعاني من عدم اهتمام الددرسة بمشاكل الطلبة & $v$. \\
\hline & & & في نيتي إكمال دراستي الجامعية & vi \\
\hline & & & اشعر بالراحة حين أنكلم مع الددرسين & VY \\
\hline & & & أحب مطالعة بعض الكتب الددرسية & $v r$ \\
\hline & & & ارغب في أن اترك المدرسة & $V \varepsilon$ \\
\hline & & & أثشارك زملائي في النشاطات المدرسية & vo \\
\hline & & & يزعجني بعض زملائي في الددرسة & $\mathrm{VI}$ \\
\hline & & & أعاني من بعد المدرسة عن البيت & $\checkmark V$ \\
\hline & & & تزعجني طريقة تدريس بعض الددرسين & $\mathrm{vA}$ \\
\hline & & & اعتد على نفسي في تحضير الواجبات الددرسية & $\mathrm{Vq}$ \\
\hline & & & ينتقد زملائي مظهري & $\wedge$. \\
\hline & & & افرح عندما يحقق زملائي أهدافهم & $\wedge$ \\
\hline & & & اشعر أن حريتي مقيدة داخل الصف & Ar \\
\hline & & & يحاول زملائي مساعدني في حل مشاكلي & ᄉr \\
\hline & & & اهتم بإرشادات الددرسين & $\wedge \varepsilon$ \\
\hline & & & أقيم علاقات صداقة مع زملاء من صفوف أخرى & 10 \\
\hline & & & أعاني من صعوبة بعض المواد الدراسية & $\Lambda 4$ \\
\hline
\end{tabular}




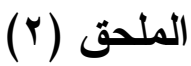

بسم الله الرحمن الرحيم

استبيان أراء السادة المختصين حول صلاحية البرنامج التعليمي لدرس التربية الرياضية

$$
\text { تحية طيبة الاستاذ الفاضل ............................................ المحترم }
$$

يروم الباحثون إجراء دراسة لدعرفة (اثر البرنامج التعليمي لدرس التربية الرياضية في تتمية التوافق النفسي والاجتماعي لدى طلبة الصف الثاني متوسط).

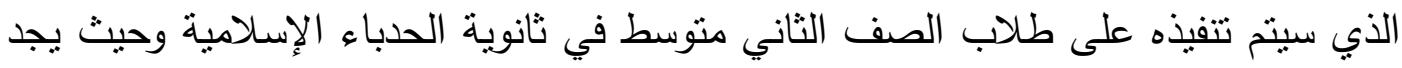

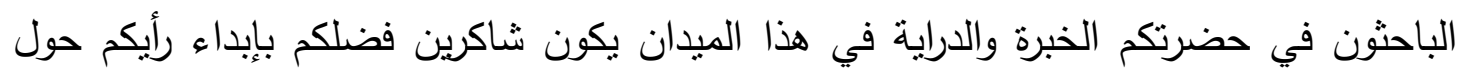

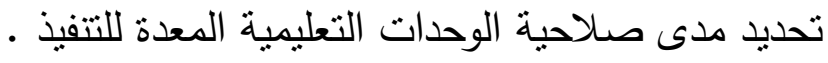

ولكم جزيل الثكر والامتنان

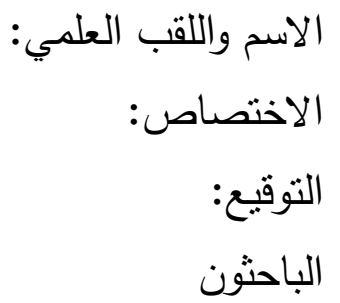




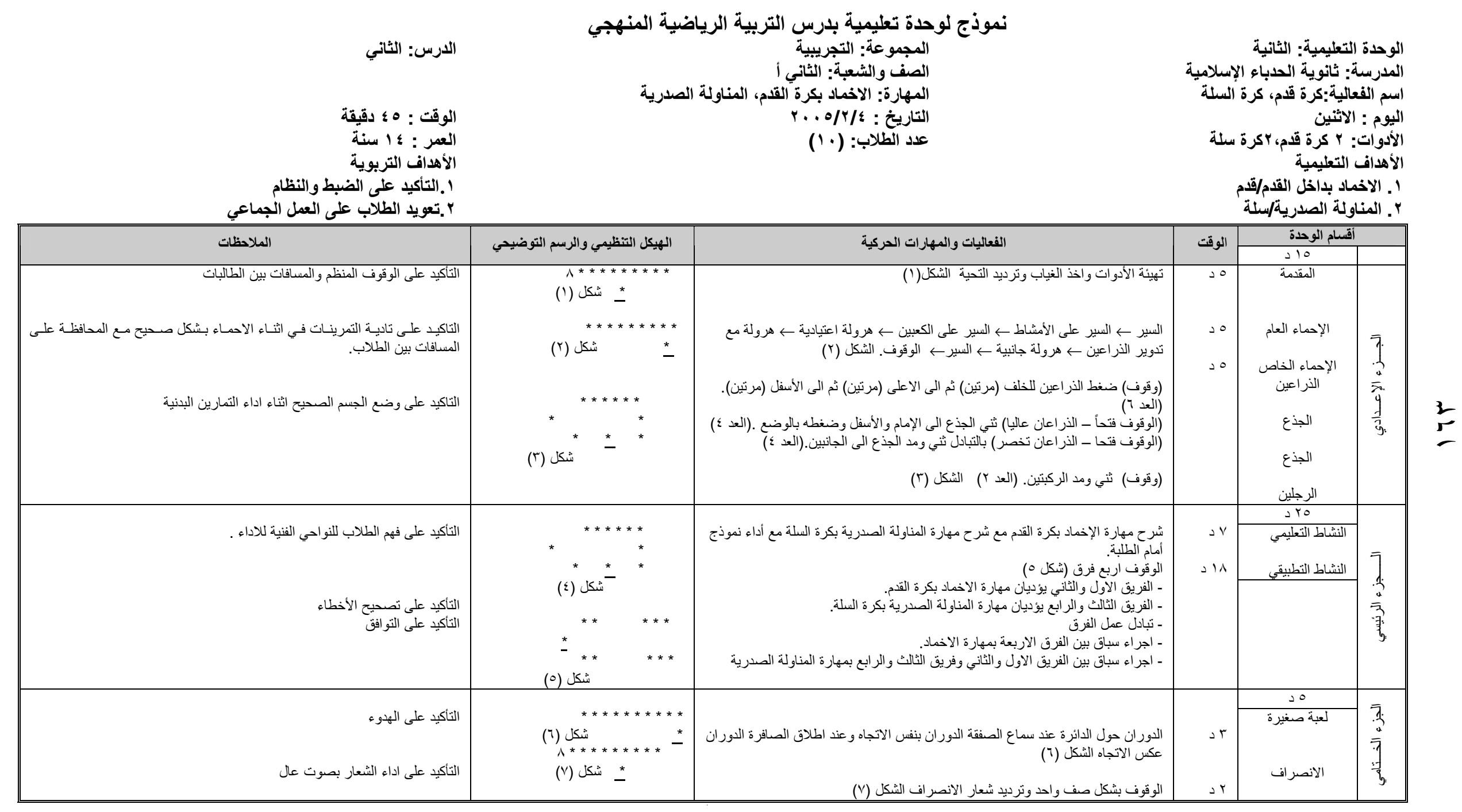

